\title{
Unplanned Potential:
}

\section{Domestic Architecture Designed for Play}

by

$$
\text { Yvonne Kearns, B.A., B.A.S. }
$$

A thesis submitted to the Faculty of Graduate and Postdoctoral Affairs in partial fulfillment of the requirements for the degree of

Master

of

Architecture

Carleton University

ottawa, Ontario

() 2012

Yvonne Kearns 
Library and Archives

Canada

Published Heritage

Branch

395 Wellington Street

Ottawa ON K1A ON4

Canada
Bibliothèque et

Archives Canada

Direction du

Patrimoine de l'édition

395 , rue Wellington

Ottawa ON K1A ON4

Canada
Your file Votre référence

ISBN: 978-0-494-87822-4

Our file Notre référence

ISBN: 978-0-494-87822-4

\section{NOTICE:}

The author has granted a nonexclusive license allowing Library and Archives Canada to reproduce, publish, archive, preserve, conserve, communicate to the public by telecommunication or on the Internet, loan, distrbute and sell theses worldwide, for commercial or noncommercial purposes, in microform, paper, electronic and/or any other formats.

The author retains copyright ownership and moral rights in this thesis. Neither the thesis nor substantial extracts from it may be printed or otherwise reproduced without the author's permission.
AVIS:

L'auteur a accordé une licence non exclusive permettant à la Bibliothèque et Archives Canada de reproduire, publier, archiver, sauvegarder, conserver, transmettre au public par télécommunication ou par l'Internet, prêter, distribuer et vendre des thèses partout dans le monde, à des fins commerciales ou autres, sur support microforme, papier, électronique et/ou autres formats.

L'auteur conserve la propriété du droit d'auteur et des droits moraux qui protege cette thèse. $\mathrm{Ni}$ la thèse ni des extraits substantiels de celle-ci ne doivent être imprimés ou autrement reproduits sans son autorisation.
In compliance with the Canadian Privacy Act some supporting forms may have been removed from this thesis.

While these forms may be included in the document page count, their removal does not represent any loss of content from the thesis.
Conformément à la loi canadienne sur la protection de la vie privée, quelques formulaires secondaires ont été enlevés de cette thèse.

Bien que ces formulaires aient inclus dans la pagination, il n'y aura aucun contenu manquant. 


\section{unplanned potential domestic architecture designed for play}

yvonne kearns

a thesis submitted to the faculty of graduate and post-doctoral affairs in partial fulfillment of the requirements for the degree of master of architecture carleton university, ottawa, ontario

() 2012 yvonne kearns 
l've been juggling the roles of wife, mother and architecture student for the past 7 years. My spouse has given me the room to be all of those things, along with encouraging me to travel to Italy for 3 months of study, cheerfully fulfilling the duties of mom, dad, chauffeur, cook and bottle washer. His sacrifices to this end have gone far above and beyond the call of duty. My children, right from the tender age of 7 , have with humor and grace learned to make their own lunches, cook dinner, do laundry, and resign themselves to having a mother who has more glue and colored pencils than they do. And so the culmination of those years of work in the form of this thesis is dedicated to:

\title{
$A L A N$ I couldn't have done it without your support and encouragement. \\ Thank-you from the bottom of my heart.
}

A INE gentle wisdom in a beautiful young woman, you are at the core of my heart.

\author{
A I D A N \\ my comfort and joy, \\ you are a gift from God to me. \\ In memory of Droste, whose life epitomized play.
}

A special thanks to Qi Zhu for advising me on this project.

The countless hours she invested, as well as her wisdom, patience, and sense of fun were instrumental in its completion. 


\section{table \\ of contents}

$\begin{array}{rr}\text { abstract } & 4 \\ \text { introduction } & 7 \\ 1 \text { (de)scripting } & 13 \\ { }^{2} \text { potential space } & 23 \\ { }^{3} \text { praxis } & 31 \\ 4 \text { housing play } & 42 \\ \text { conclusion } & 63 \\ \text { appendix } & 65 \\ \text { list of figures } & 71 \\ \text { bibliography } & 74\end{array}$

unplanned potential」 「yvonne kearns 2012 


\section{abstract}

Why do so many of us appear content to live in repeated rows of domestic homogeneity, particularly in suburbia? Have these recurrent domestic forms repressed our imagination? The house, as the primary place of human dwelling, is clearly one of the most influential architectural environments in our lives. Yet it has become more or less a unit of monetary exchange which, while satisfying the basic domestic functions, is designed primarily for profitability, resulting in obvious patterns of predictability.

Might we consider the cultivation of play in the home environment to be one of the ways in which to dislocate this convention? Play will be analyzed in this thesis as a potential modus operandi of imaginative engagement with creative potentialities, rather than as a particular type of activity. The introduction of malleability, engagement and the selective deconstruction of boundaries within a domestic space are investigated as a means of designing for play. The thesis experiments with the efficacies of malleable boundaries directly manipulated by the inhabitants in

unplanned potential」 「yvonne kearns 2012 
transforming the house, allowing for constantly evolving alternative modes of dwelling.

The house, rather than passively shaping the choreography of our daily domestic performance, could in this way playfully challenge the conventional living patterns and present the previously unimagined. This might then allow the semiotics of home and dwelling to be redefined by the user on a continuous basis, allowing the dweller to shape a fuller, richer and more playful manner of living.

unplanned potential」 「yvonne kearns 2012 


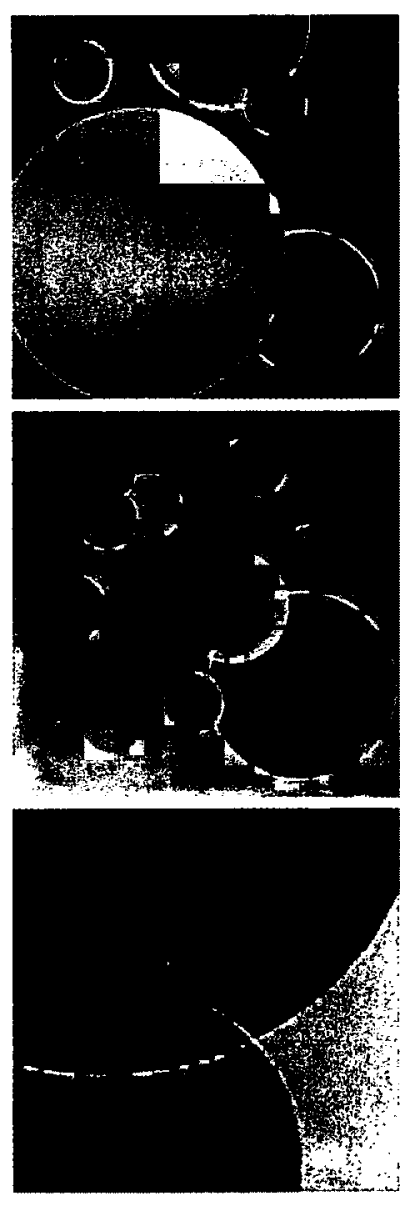




\section{introduction}

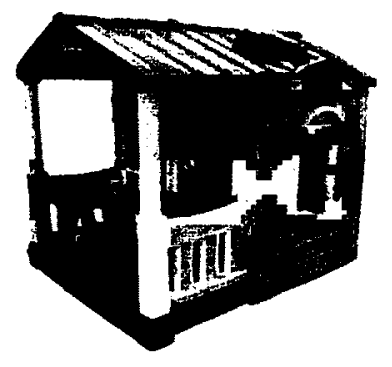

Julie wakes up to an enormous wrapped gift on the morning of her sixth birthday. A frantic ripping of paper and discarding of bows reveals the dream birthday gift - a toy playhouse just her size. There is a tiny doorway that she must duck her head to fit under. There is a miniature kitchen, complete with tiny sink, toy stove, and pretend plastic food. The windows have charming blue shutters which coordinate beautifully with the pale yellow plastic exterior. The playhouse appears to be everything of which a little sixyear-old could dream. Julie is thrilled; she spends 30 minutes in industrious engagement with the house, and then boredom edges its way in. The rest of the day is spent in abandoned bliss, cutting, taping and coloring the box in which the toy house came. Crooked windows are cut from the side. Leftover scraps of wrapping paper are used to make crinkly curtains. Flowers bloom in paper splendor along the side. Julie is enormously pleased with her singular masterpiece.

Julie's interaction with the plastic toy house is relatively one-dimensional. The toy house, by nature of its design, embodies a pre-defined narrative of play. Julie is content to

unplanned potential」 $\Gamma_{\text {Yvonne kearns } 2012}$ 


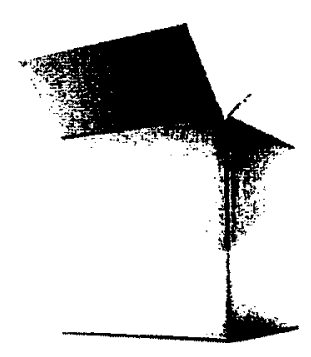

participate within these parameters for a limited period of time. She dramatizes the familiar chronicle of domestic activities and chores that are suggested by the object with which she has been presented. Since the story is strongly delineated by the form of the toy, Julie simply acts out her interpretation of it. Variation is present only in a repeated reinterpretation of the assigned narrative.

The cardboard box, on the other hand, presents a far more open-ended setting for play, one which allows for multidimensional interaction. The story has yet to be developed. The box suggests a framework; it provides hints and clues, it presents opportunity, and allows Julie to form her own definition of play. Julie develops a unique and personal narrative within this framework. She responds to the malleability of the box by reshaping it with scissors and tape and glue. The nature of the cardboard invites her to embellish it with markers and paint. By the end of the day, her story has begun to take shape. But it hasn't ended; rather, there is merely an intermission. The narrative she has developed with the cardboard house retains its potential for change, and on a later day is available for further development, becoming a space ship, or a race car, or a fort beside her bed. The cast, characters, set, and dramatic narrative are open to continuous transformation, providing recursive opportunities for imaginative play.

Children are delightful in their ability to transform almost any situation into an opportunity for play, adeptly reappropriating the various objects in their world to use as tools to facilitate engagement and fun. Even in the most dire of circumstances, children will find a stone, or a piece of refuse, and use it as a play object. As confirmed by the cardboard box, it is apparent that the less definition associated with an object or play setting, the more imaginative the play can be. Play which presents a certain 
- The 'open plan' is something of a misnomer. It implies freedom and openness, when in fact it is merely disguises its boundaries as changes in lighting, flooring or fenestration. amount of challenge is more enticing, and an open-ended play setting draws on the creativity and imagination of the player to develop their own parameters for play. ${ }^{1}$ Christine Tandy of the University of Newcastle in Australia reports that children with flexible play environments learn to generate fun from within their own imagination. ${ }^{2}$ A play opportunity that is open-ended provides the child with a 'broadening spectrum' of play, which nurtures a 'free-flowing' imagination. ${ }^{3}$ Overly prescriptive play, on the other hand, narrows a child's repertoire of responses to the world. According to Stuart Brown, the optimal play environment offers maximum freedom within boundaries which are sufficient to provide a feeling of safety. ${ }^{4}$ Thus, within the natural tendency to play, certain more abstract objects and environments can further nurture a more imaginative and rewarding play experience. Just as certain un-prescribed situations lend themselves to playful engagement for children, this thesis investigates how a less architecturally circumscribed living environment can cultivate play in the lives of the inhabitants.

Currently, most houses present a fixed stage set for daily life which is often designed by development corporations, particularly in suburbia. These homes have an analogical parallel with Julie's plastic house, directing the prewritten drama of daily life rather than providing the framework for the inhabitants to shape their own daily narrative. The nature of modern housing often offers an abundance of imposed programmatic barriers, both real and implied.$^{5}$ Lars Lerup points out that the house plan formula seems to follow a well-used pattern - the garage is at the front of the house, often protruding past the front door. The family living spaces are generally at the back of the house. The sleeping spaces are upstairs, with a larger bedroom for the adults and smaller ones for the children. ${ }^{6}$ Play spaces, other than those dedicated to television watching and other

unplanned potential」 「yvonne kearns 2012 
passive activities, are often designated for the children and usually relegated to the basement, if they factor into the design at all. While this formula may not be problematic at first glance, it's ubiquitous presence can suppress our capacity to imagine alternative ways of living.

Suppose we withdraw the imposed narrative. Imagine the domestic boundaries being stripped to their bare essentials. A house that offers a series of open and intriguing options and questions rather than a formulated scenario leaves space for the dweller to step in and imaginatively develop their own storyline. The semiotics between dwelling and dweller becomes open for continual redefinition and reinterpretation. The imagination is thus stimulated, and possibilities for a more engaged way of living present themselves.

When domestic space is designed to cultivate play, daily acts of routine can become playful. Beyond being just plain fun, a house that cultivates playful living has the potential to enhance to the richness of our lives, as well as benefit our physical and emotional health, our social intelligence, and our cognitive abilities. D. W. Winnicott, a 20th century pediatrician and psychoanalyst, identified play as 'the essential thing in human life that makes life worthwhile, that which lights the path of the individual search for self'. ${ }^{7}$ Winnicott called this notion 'living creatively' ${ }^{8} \mathrm{He}$ suggested that only in playing is the individual free to be creative, and only within the realm of creativity is life worth living. ${ }^{9}$

Play, in this thesis, is conceived as an approach or modus operandi, rather than an isolated activity. With this perspective, play is able to permeate all aspects of life, even those which are traditionally thought of as tasks of necessity. Play as a modus operandi can become an agent of pleasure, stimulation and imagination. By incorporating play

unplanned potential」「yonne kearns 2012 
into domestic architecture we can explore how a home environment can provide opportunities for playful moments, and even add a playful element to the traditional tasks of necessity.

This playful and engaged type of domesticity might provide the link that Martin Heidegger suggests is missing between

dwell 'building' and 'dwelling', enabling us to 'bring dwelling to verb l'dwell

1: to remain for a time 2 a: to live as a resident b: exist, lie 3 a: to keep the attention directed b: to speak or write insistently the fullness of its nature,11. The physical reality of the house and the deeper dimension of 'full' or meaningful living might establish an inexorable and mutually profitable connection. Engagement in the manifested form of our living space could enable full and meaningful dwelling, because, as Heidegger said, 'to build is in itself already to dwell,12. Thus our physical dwelling might become a participant in the way in which you are and I am, the manner in which we humans are on the earth ${ }^{13}$.

We will therefore investigate architecture's capacity to cultivate 'meaningful dwelling' through initiating and cultivating a playful life in the domestic architectural environment. Within the home environment, the traditional static spatial barriers, which shape a pre-prescribed domestic narrative, can be replaced by operable boundaries. The home design will seek to incorporate innovative interactivity between the architectural elements and the dweller. This changeability has the potential to generate a playful manipulation of the house by the dweller and give rise to creative programmatic overlap. The customary use of materials is analyzed, and their association with play is investigated. In this way, play is implemented as a design tool to perpetuate a semiotic relationship of creativity, engagement and play between dweller and dwelling.

unplanned potentialı $\Gamma_{\text {yvonne kearns } 2012}$ 
All the world's a stage, And all the men and women merely players: They have their exits and their entrances; And one man in his time plays many parts.

William Shakespeare

unplanned potential」 $\ulcorner$ yvonne kearns 2012 


\section{${ }^{1}$ (de) scripting}

mo $\cdot$ dus ope $\cdot$ ran $\cdot d i$

noun

I,mō-dəs-,ä-pə-'ran-dē,-,dn

1: A method of operating or functioning.

2: A person's manner of working.

en - gaged adjective

lin-'gājd, en-l 1: involved in activity 2: pledged to be married 3: greatly interested 4: involved especially in a hostile encounter 5: partly embedded in a wall 6: being in gear
As adults, we have most likely left cardboard boxes and play houses behind, and play no longer seems to come quite so naturally. While play in children is universally identifiable, even across cultural and language barriers, ${ }^{14}$ the same cannot be said about play later in life. How might play be identified in the life of an adult? Adult play might be present in many traditionally playful situations, such as sports and games, but the concept of play cannot be restricted to a certain type of activity. What for one person might be a dreaded necessity might for another be a playful encounter. Thus, play is not characterized as an activity but rather as the approach or modus operandi to an activity, that is, the playful manner in which an activity is carried out. Musician and philosopher Stephen Nachmanovitch suggests that 'play is not the name of an act or action, it is the name of a frame for action...play is the way we do it or say it, whatever it may be. 15

The modus operandi with which we approach an activity to render it playful is a form of engagement. Engagement enhances our personal narrative in such a way as renders it multi-dimensional, more meaningful, and of greater pleasure.

unplanned potential」 「Yvonne kearns 2012 
Most theorists concur that if our engagement in an activity is both voluntary and pleasurable, then play is at play. Some narratives might be naturally playful, and we can simple pick them up and run with them. However, even when the basic form of the plot is dictated to us by necessity, we have the opportunity to amend or embellish it, to imbue it with playful engagement. A man waiting in line at the grocery store might start up a banter with the individual behind him. His interaction with his fellow shopper is playful in nature. He has exerted his freedom to change the linear narrative of

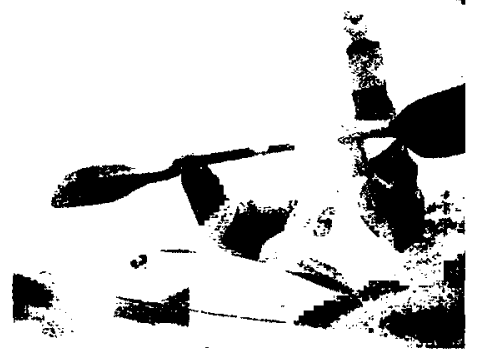
his errand, enriching and enlivening it with his playful gesture. When play is viewed as a modus operandi, even mundane activities have the capacity to become playful. In fact, play can crop up in some unique and unexpected places, as evidenced by the following account.

My cousin Sanne, a competitive rodeo kayaker and highly energetic person, had a summer job as a road crew worker a number of years ago. Her job required her to stand in the burning sun, or the pouring rain, with a stop sign in her hand, directing the traffic through a construction site. Knowing Sanne to be an intensively athletic type of person, I once suggested to her that this job must have been torture for her. The monotony, the boredom seemed in direct contrast with her lively character. To my surprise, Sanne's eyes lit up in memory of her summer on the road. She explained that the job had been one of her favorites. She had chosen to engage in conversation with each driver at the front of the line. She met some fascinating people. She shared jokes. She made new friends, finding like-minded people to paddle or cycle with once her working hours were through.

Sanne's approach to a tedious job was playful in nature. This playful modus operandi transformed what for others might have been an agony of boredom into an opportunity for fun and engagement. Sanne chose to re-write the narrative of the traffic controller, to lend it her own flavour, to shape her work day in a way that provided the stimulation and benefits of play.

unplanned potential」 「yonne kearns 2012 
Despite his assertion of play as 'unreal', Huizinga might be thought to form a connection between play and real by suggesting that within the pretense of play there may exist to greater or lesser extent an element of seriousness. He proposed that

the contrast between play and seriousness is always fluid. The inferiority of play is continually being offset by the corresponding superiority of seriousness. Play turns to seriousness and seriousness to play.'

This suggests that play might encompass a measure of solemnity, yet it does not identify the essential link between play and reality. Huizinga's 'seriousness' is not a link with reality, but rather the emotion accompanying an act of play. Thus a chess game might be played with intense seriousness and concentration, but Huizinga would define the game as 'only pretense' non-theless. According to his theory, the fictional narrative of war that the game is based on removes it from reality. However, I would suggest that the pretense of the game of chess is merely a tool, a modus operandi, with which the players are connecting to each other and to what is real. Their interaction during the game, their manner of winning or losing, are a elements of their respective realities that owe their existence to the game of pretense. These realities are benefited and enriched by their playful engagement with the game of chess.

A Huizinga, Homo Ludens, 8
In apparent conflict with the view of play as modus operandi available to any activity is the commonly held idea that play is in essence a separation from real life. Anthropologist Edward Norbeck suggests that play is 'distinct in having a make-believe or transcendental quality'. ${ }^{16}$ Johan Huizinga, an eminent cultural historian and play theorist, suggested that one of the defining characteristics of play is that it is an enigmatic withdrawal from the everydays', that it is 'a stepping out of "real" life into a temporary sphere of activity with a disposition all of its own'18. Huizinga's notion of play encompassed both temporality and pretense, suggesting that play can be extracted from normal everyday life as an isolated activity. Huizinga proposed that an activity is either 'only pretending' and thus play or it is 'real life' and thus not play. Children might engage in a fight, expressing genuine anger and violence. The fight is real and therefore not play. Alternatively, they might have a play fight, acting out feelings that they do not in reality possess. This, according to Huizinga, is pretense and is therefore play.

I would suggest that play, even when it gives the appearance of pretense, is firmly rooted in reality. When children are play fighting, they have not left reality behind and entered a parallel fictional universe. Rather, their play exists in the gap, in the space that has been created between the real and the pretend. In their play, they are engaged in the connections between the playful pretense they are acting out and the reality in which the play is grounded. D.W. Winnicott's book Playing and Reality addresses the space between the real and the pretend, which he termed potential space. He suggests that the potential space between a mother and child in infancy is the child's playground and the place for the healthy development of the child. In adults, the

unplanned poi ential」... ryvonne kearns 2012 
pre tend verb Ipri-'tendl

1: to give a false appearance of being, possessing, or performing

2: to make believe 3: to feign an action, part, or role especially in play potential space is the realm between reality and illusion; this is the adult's playspace. Winnicott suggests that the key element of this playspace is 'the paradox, and the acceptance of the paradox ${ }^{19}$, which allows the player to gain understanding through reality-testing. Within this playspace lies an apparent contradiction. For instance, the chore of doing the dishes after dinner can approached through the modus operandi of play by transforming it into a playful race. The monotony of the task is relieved, and those participating in the task are able to test the reality of the monotony of the chore through the pretense of friendly competition. In turn, the actuality of the boredom of this particular household task is amended and it becomes a source of pleasure and social interaction.

This contradiction is also evinced in a game of soccer, where the soccer field is both a battle ground and not a battle ground. It is the place of combat, but also the place of sociability and play. The soccer ball is both an inanimate object and a prize for which is player is willing to risk bruised shins. The paradoxical nature of the game permits a type of interaction with others that would be unimaginable outside of the play arena. Engaging with these contradictions allows the player to act out the narrative of aggression, to pursue the goal with a physical and emotional intensity that would unlikely exist in the 'real' world.

Winnicott calls the manner in which the player occupies the intermediary zone the 'transitional phenomena' ${ }^{28}$. Thus,

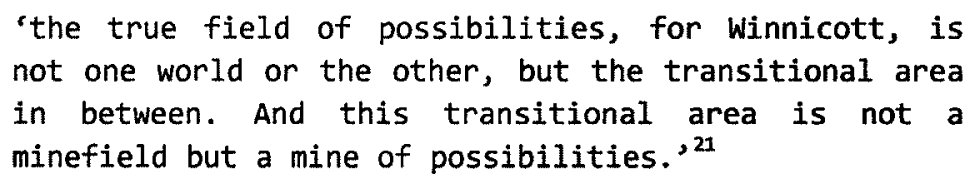

Occupation of the space between reality and pretense provides the freedom to operate without the causality that would exist outside of the play arena. The illusory or imaginative nature

unplanned potential」 「yvonne kearns 2012 
of pretense makes the act of play a type of rehearsal, where mistakes can be made and learned from. In occupying the gap we can view the 'real' objectively from the unique vantage point of our playful pretense. We can experience an abstracted reality wherein we can test our circumscribed boundaries. This playful abstraction of reality teaches us to reason in a flexible manner. ${ }^{22}$ Through it we gain social intelligence, discerning how to express our feelings and perceive those of others. ${ }^{23}$ Strengths and limits can be tested within the playful narrative. The unexpected is stumbled upon and can be embraced. Within this domain, our engagement with reality through pretense can loosen our inhibitions, challenge the societal norms and open the door for critical reflection on our current reality and its various future potentials. To occupy that space, to engage with reality from an abstract vantage point, that is play. Play, seen thus, is indeed a part of reality. Even play that appears on the surface to be nothing more than just a moment of pure pleasure is none-the-less a modus operandi; it is the approach that is made to the reality of the moment. It is play's essential connection to reality that gives it its worth and that allows the fruits of play to be integrated into our everyday life. The value of play is in its ability to disclose, examine and test our circumscribed reality, and to expand and transform that reality to its furthest possible reaches.

The benefits of play are strengthened when they include sociability. Humans are fundamentally social creatures. While some solitude is necessary and good, interaction with others in the form of play provides the challenges and feedback necessary for emotional health and effective social skills. As reported by Mihaly Csikszentmihalyi, 'socialization shapes behavior and molds consciousness'. ${ }^{24}$ Huizinga suggested that play can generate a feeling of capart together', where a social play situation results in a mutual

unplanned potential」 $\Gamma_{\text {rvonne kearns } 2012}$ 
connection that is somehow sacred and magical. ${ }^{25}$ Social play promotes connections with those around us and hones our communication skills; it teaches us to verbalize our feelings and to empathize with others. It promotes the development of empathy, trust, problem solving abilities, and the ability to grasp irony. Even physically combative social play can be productive when it fosters 'creative tension'. ${ }^{26}$ In fact, social play deprivation in the early years significantly decreases later intellectual ability, an assertion which makes the pretense of play very much a part of our reality.

The connection between the pretense of play and everyday reality is borne out by the body's physiological responses to play. There is a physical stimulation of right hemisphere brain activity during certain types of play. ${ }^{27}$ Connections within the cerebellum \& pre-frontal cortex are said to be activated by physical movement. ${ }^{28}$ Play "promotes brain and cognitive vitality well into older adulthood." 29 The obstacles and challenges provided by playful activity are necessary for the proper functioning of our nervous system. ${ }^{30}$ In fact, a deficiency of play gives rise to a higher rate of reported illness and depression and a rise in levels of pain for those fighting cancer. ${ }^{31}$ Individuals deprived of play are shown to develop a rigid reaction to complex stimuli. ${ }^{32}$ As well, their list of choices is perceived to be narrower than reality indicates, and they do not seek out novelty, all of which reduces their ability to adapt to their environment. ${ }^{33}$

Play's function in testing boundaries and enhancing mental capacity is precisely what makes it so valuable in certain traditionally non-playful spheres of life. It is well established that play has immense power to influence and improve our working lives, making work not only more enjoyable, but also more productive. ${ }^{34}$ Play has been strongly linked to creativity. ${ }^{35}$ It enhances problem solving ability and fosters flexibility and innovation. ${ }^{36}$ Studies of play in

unplanned potential $\rfloor$ 「yonne kearns 2012 
the workplace by Charalampos Mainemelis and Sarah Ronson have shown play to 'facilitate the cognitive, affective and motivational dimensions of the creative process,37. They suggest that an attitude of playfulness will suspend expected conventions, freeing individuals to behave in ways that are inconsistent with the norm. These freedoms, they suggest, pave the way to creativity. As described by Mainemelis and Ronson, play in the workplace is essentially a type of suspended reality. An engagement with playful pretense superimposes an added level of abstraction to work, changing its boundaries, dynamics and creative potential. These benefits are critical for creative and analytical jobs, but also, as in Sanne's case, can provide benefits to mundane work. This vital connection is demonstrated in the following:

Play at work was unintentionally utilized by Daina Taimina, a mathematician at Cornell University. The playful activities of knitting and crochet, carried out while at work, led her to the discovery of a way to model hyperbolic space. Her woolen model gave material evidence contradicting Euclid's 5th postulate, something which scientist had been trying to do for hundreds of years. Margaret Wertheim, who describes this discovery in a lecture at Ted Talks, suggests that

We Iive in a society now where we have lots of think tanks, where great minds go to think about the world. ...We want to propose... another alternative way of doing things, which is the play tank. The play tank, like the think tank, is a place where people can go and engage with great ideas. But what we want to propose, is that the highest levels of abstraction, things like mathematics, computing, logic, et cetera -- all of this can be engaged with, not just through purely cerebral algebraic symbolic methods, but by literally, physically playing with ideas. ${ }^{38}$
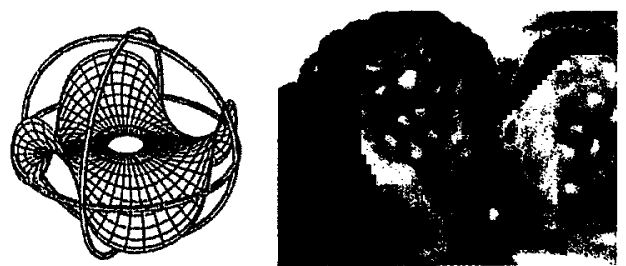

unplanned potential」 「yvonne kearns 2012 
Play also plays a key role in education, and has been perpetuated as such since antiquity. Plato bestowed upon play the role of teacher of philosophy, which is the science of being. ${ }^{39}$ I have found a prime example of play's capacity to enrich education right here at Carleton University's architecture school.

I remember my heart beating just a little bit faster when I read the course list for the undergraduate degree. Drawing. Photography. Videography. Graphic Design. Wood shop. Metal work. Travel to Montreal. And New York City. And Portugal. It sounded like heaven to me. If this was how to get a respected degree in architecture, I was in.

Despite the reality being a bit more strenuous than I had imagined ( 80 hours a week might be a bit too much of a good thing), my conclusion has been that the education I received from all that play is a model of what education should look like. Yes, there were the practical courses needed to learn the basics of civil engineering. There was some art history, and a bit of philosophy. I was taught which side of the wall the insulation should go on.

Fundamentally, though, I learned by playing with materials, by drawing and through impassioned debates with my peers and instructors. No professor ever dictated, 'this is how to design a good building'. Ever. Trust me, I asked. It took a while to realize that being handed the information would have been a waste of time. The learning happened in the midst of the glue and the balsa wood and the modeling clay and the dark room and the nicks on my fingers from the sander in the wood shop. Want to learn? Play. Want to play? Go to architecture school.
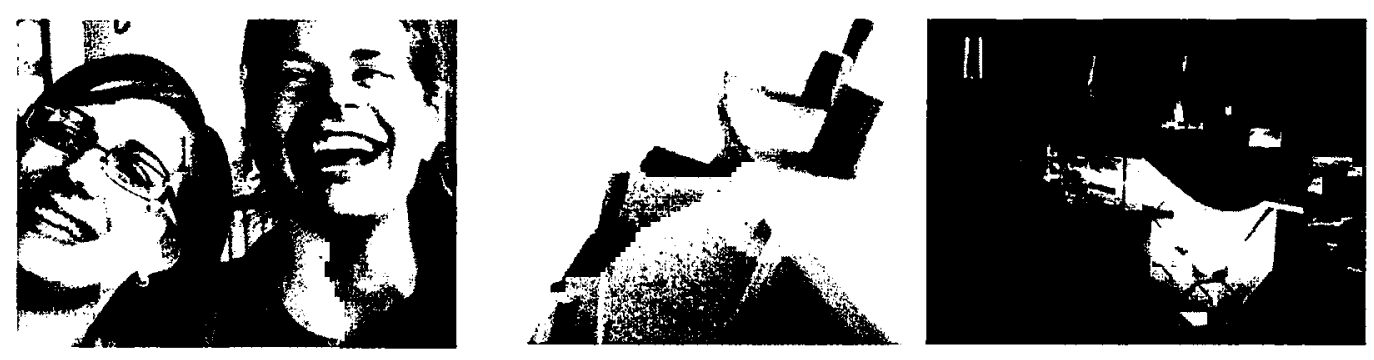

unplanned potential」 「yvonne kearns 2012 
A look at the animal world will show that, for many species, play has managed to survive natural selection. Many animals participate in play in one form or another, even when to do so puts their lives at risk. Mountain goats, for example, periodically fall to their deaths during play, and yet the inherent danger in play has not eradicated it from the species. ${ }^{46}$ This suggests that 'play' plays a critical role in survival beyond the pleasure and stimulation it affords. In fact, some animal behaviour seems to indicate that play preempts food as an instrument of survival. Evidence for this is reflected in the following:

On a late October day on the Canadian tundra next to a gray, cold, but unfrozen Hudson Bay near tiny Churchill, Manitoba, a pack of large Husky dogs were comfortably lounging on a fresh bed of snow.

The dogs' owner watched as a twelve-hundred-pound polar bear quickstepped across the snowfield, straight toward the sled dogs. That fall, the polar bears in the Canadian far north were hungry. The sea had not yet frozen, denying the bears access to the seals that they hunted from the ice. Judging from the appearance of this particular bear, it had not eaten in months.

But one of the dogs, Hudson, had other things on his mind. As the polar bear closed in, Hudson didn't bark or flee. Instead, he wagged his tail and bowed, a classic play signal. Astonishingly, the bear responded to the dog's invitation. Bear and sled dog began a playful romp in the snow.

After fifteen minutes, the bear wandered away, still hungry, but seemingly sated by this much needed dose of fun. Even more astonishing, the same bear returned the next day at around the same time for another round of frolicking with Hudson. Every night for a week, the polar bear and Hudson met for a play date. Eventually, the ice on the bay thickened enough for the famished but entertained polar bear to return to his hunting grounds for seal.

unplanned potential」 $\Gamma_{\text {yvonne kearns } 2012}$ 
A further value of play beyond pleasure, pretense and intellect is its 'profoundly aesthetic quality'41. Huizinga suggested that 'play has a tendency to be beautiful, 42, and that it is a 'temporary perfection'43. Plato 'exalted play to the highest regions of the spirit'. ${ }^{44}$ This side of play positions it beyond logic and highlights its ability to add to the beauty and depth of life. Brian Sutton-Smith suggests that the beauty and pleasure of play is in its 'release of restraint ${ }^{45}$. Even Stuart Brown, who approaches play from the standpoint of science, believes that 'play can be a glimpse of the divine'. Huizinga stated that 'play is an integral part of life in general. It adorns life, amplifies it. It is a necessity because of the meaning it contains, its significance, its expressive value'. ${ }^{46}$

unplanned potential」 「yvonne kearns 2012 


\section{${ }^{2}$ potential space}

Genuine buildings give form to dwelling.

Martin Heidggger

Definitions are a way to postpone thinking, never mind seeing.

George Stiny
The connection between architecture and play is embedded in the association between architecture and human behaviour, being and identity. Architecture holds meaning far beyond its presence as a functional object. As both a reflection and conductor of human life and culture, it holds enormous value in the semiotics of human dwelling. The home, as the vessel of our dwelling, is not a benign artifact that merely reflects style and taste. It plays a part in molding our behaviour and shaping our being and identity.

Amos Rapoport, an American architectural theorist, suggests that an architectural setting is
'a milieu which defines a situation, reminds occupants of the appropriate rules and hence of the ongoing behaviors appropriate to the situation defined by the setting. The setting frequently provides the appropriate props for these behaviors and activities. The cues in setting act as mnemonics - they remind those entering the setting of the situation it defines, of which rules apply and hence of how to act. ${ }^{47}$

Architecture plays these roles in shaping our behaviour in ways of which we may not be conscious.

unplanned potential」 $\Gamma_{\text {yvonne kearns } 2012}$ 


\footnotetext{
${ }^{\circ}$ The affordances of anything are those of its properties that enable it to be used in a particular way by a particular species or an individual member of that species. The properties of concern are the physical properties of the configuration of an object or setting that allow it to be used from some overt activity. They also afford meanings and aesthetic appreciation. The affordances of a physical setting are what it offers for good or ill because of the characteristics of its configuration and the material of which it is fabricated. Louis Kahn used the term availabilities in much the same way.
}

Jon Lang
The boundaries within an architectural setting overtly and definitively impact the daily domestic activities they house. They influence their order, arrange the segues between them, shape the ways in which they are linked or divided and direct where and when they take place. Jon Lang, an architectural theorist from the University of Pennsylvania, terms this 'the affordances of the environment 0.48 Architectural form that does not allow variance in conventional behavioural patterns becomes deterministic; it dictates the manner in which it is inhabited.

Beyond the definitive impact bounded space exerts on physical and social human behaviour are the more subtle hints and clues it conveys to our perception and cognition, further affecting the encompassed behaviours. For example, architectural tectonics can restrict the presence of natural light, creating a space that is perceived as private and inaccessible to guests; the use of particular colours or materials can define a particular space as formal, discouraging a group of teenagers from congregating there. The physical presence of a breakfast bar in a kitchen affords a space for eating. The cultural meaning embedded in that eating space defines it as a casual family setting, inappropriate for serving a meal to company. In these examples, architectural space embodies subtle meaning which presents its own affordances, perpetuated by messages of convention and routine embodied in their form, aesthetic and materiality.

An architectural setting can also exert a decisive impact on the encompassed social interactions. Through both formal and subtle means architecture becomes an instrument of socialization through which cultural values and behavioural conventions are transferred from generation to generation. ${ }^{49}$ While not all behaviour is directly subservient to cultural 
A net of checks (rooms) and balances (doors), the plan forms the fundament of order and discipline for the family. Despite this obvious power in our lives, despite the incessant repetition of tis syntax, the plan is taken for granted and is therefore experienced on the edge of our everyday consciousness.

Lars Lerup

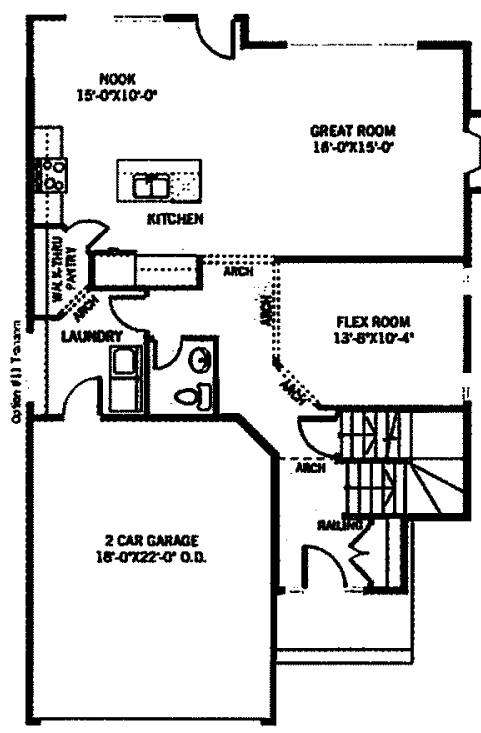

norms and expectations, and behavioural deviance does exist, the impact of architecture on behaviour is undeniable.

Not only do our domestic environments guide the rhythms of our daily routines, they have certain influence in the shaping of our being and identity. Heidegger identified a connection between our buildings and our being by virtue of the shared German root of the words 'to build' and 'to be'so. He suggested that 'building is not merely a means and a way toward dwelling - to build is in itself already to dwell, ${ }^{, 51}$. His solution for the 'plight of dwelling' is 'to build out of dwelling, and think for the sake of dwelling'. 52 Dwelling, according to Heidegger, is not an activity which is isolated within the home. Rather dwelling is 'the way in which you are and I am, the manner in which we humans are on the earth'. The manner of our 'inhabitation' provides the 'habits' that configure our lifestyle and identity. Judith Attfield, of the University of Southampton, suggests that the 'domestic interior is a cultural symptom of the dynamic process of social identity formation". 53

These inherent boundaries, cues and symbols which guide and shape our identity, being and mode of inhabitation have in many cases been left to be prescribed by housing development companies and the dictates of the market. House design is often based largely on economic factors. Avi Friedman, in his book The Adaptable House, has identified a number of elements of standard house design which are financially based. The square or rectangular floor plan is popular because it requires less materials for the envelope and reduces heating costs. ${ }^{54}$ The design of multipurpose rooms, the close proximity of areas requiring plumbing, and the use of built-ins to reduce space are all design strategies that are based on economy. Furthermore, the perceived value of much of our housing is embodied in its measurability, its calculated square footage, its monetary and resale values. An internet

unplanned potential」 「yvonne kearns 2012 
- Realtor.com lists five home purchase considerations'.

Four of these considerations are based on appreciation and resale factors. search for advice regarding choosing a house for purchase revealed an overriding emphasis on potential appreciation and resale value as a determining factor in selecting a home ${ }^{0}$. While economy is an important factor in house design, particularly when environmental impact is taken into account, it must be balanced with issues of human dwelling. An overemphasis on economic factors corrupts the true semiotic significance of the home as a participant in behavioural affordance, identity formation and manner of being. Within these economical design parameters, friedman reports that 'the building industry fell into a traditional conservative pattern where an acceptable limited number of house types was the norms. 55

Houses follow a well-used and repetitive pattern. The recursive homogeneity evident in corporate housing developments suggests a fixed uniform collective identity, disregarding individual variations in domestic behavioural patterns. Charles Moore, Gerald Allen and Donlyn Lyndon, in their book The Place of Houses, write that,

the legitimate purpose of architecture [is] to lay
special claim to parts of the world. We have
overbuilt, and often built so badly that... we have now
made a world in which the most alien things are what
we have built for ourselves. Most of it has no message
for us. We can't claim it as our own, and we can't
comfortably inhabit it. Thus the legitimate search for
roots has become frantic, as people seek to anchor
themselves in an increasingly bland and
undifferentiated geography.

Despite the emergence of blended and non-traditional households, house design remains based on the archetypal family unit and its corresponding conventional value assignments. Lars Lerup, from the Rice School of Architecture, theorizes that 'the single-family house is a "disciplinary mechanism" - morality manifested in form". $56 \mathrm{He}$ suggests that these values are reflected in the formula which

unplanned potential」 「yvonne kearns 2012 
- Lozano-Hemmer is speaking on an urban scale here, but the concept has similar application to the domestic scale dictates that 'the garage is as large as or larger than the living room, beds grow wider with status and age, the master bath is larger than the family bath'. ${ }^{77}$ The house design formula, while perhaps not quite the tool of 'tyranny' that Lerup suggests, requires rethinking, not only in terms of its form, but also in terms of its static nature.

Based on Heidegger's notion that 'to build' and 'to be' are intimately connected, a dweller will gain complicity with the form and character of the dwelling. The house currently exists as an architectural object, built according to outdated ideas and values, and designed to stay that way. The house as a place for dwelling must gain a vicissitude that would permit the dweller to engage in a playful dialectic with its physical form and inherent meaning. This will allow for an ongoing reinterpretation of space and its resultant behavioural patterns and mode of being. Emphasis must be placed, as Paul Klee suggested it should, on the process of genesis and growth rather than the resultant form. ${ }^{58}$ The architect must gain control of the design of domestic architecture from the hands of corporations and establish a more direct connection between the dweller and dwelling. This must be accomplished, however, in order to surrender control of the static form of the architecture into the hands of the dweller. Chuck Hoberman suggests that 'our design medium is behaviour itself, ${ }^{59}$. I would further this statement to suggest that the architect's role is not to design behavioural patterns, but to design the pre-conditions for dwellers to continually develop and transform their own behavioural patterns. In order for architecture to become less deterministic, Lerup proposes that 'designers must relinquish control of the meaning making to the dwellers themselves'. ${ }^{60}$ Raphael Lozano-Hemmer' advises that we 'provide places where unpredicted behaviours occur'. ${ }^{61}$ Rather than designing the outcome, the architect can outline the initial conditions which allow for a continuous sequence of endless variations.

unplanned potential」 「Yvonne kearns 2012 
se $\cdot \mathrm{mi} \cdot$ ot $\cdot$ ics

noun

|-'ä-tiks|

1: a general philosophical theory of signs and symbols that deals especially with their function in both artificially constructed and natural languages and comprises syntactics, semantics, and pragmatics
Attfield suggests that 'we should be thinking of it as undesign, or design waiting to happen,62. In order to free domestic life from the orthodoxy of convention, the architect can design a spatial framework, leaving the door open for a multiplicity of manifested realities which can shift and alter at the will of the dweller. As the house form changes, some of the complexities inherent in dwelling are clarified over time and from different vantage points. In this way, space is no longer constricted by a dictated form. It allows the dweller to engage in an imaginative semiotic playful relationship with domestic space and modes of dwelling.

If our built dwellings directly shape our behaviour and identity, playful architecture will have a similar efficacy. Yet there is an important difference - the unrestricted nature of an architectural playspace as interconnecting reality and pretense frees the player from the fixed social mores to embrace alternative potentialities. As Huizinga suggests, 'inside the circle of the game the laws and customs of ordinary life no longer count'.63 Where traditional architecture might disseminate ingrained ideas about how to live, architecture we can engage with allows us to gain a hand in our personal mode of dwelling. In the same way that the gap between pretense and reality creates a place for play, architecture which cultivates playful engagement emancipates our identity from being shaped by convention. We lose our subjective outlook and our dwelling develops a more purposeful meaning. It is only when we become active participants in the building or shaping of our domestic space that the semiotics of the dweller/dwelling relationship becomes mutually dynamic.

When play is applied as a modus operandi to domestic life, many of the necessary mundane tasks can become flexibly situated within the potential space. Malleable and fluid living spaces can accommodate and perpetuate the adjusted

unplanned potential」 $\Gamma_{\text {yvonne kearns } 2012}$ 
reality which is the fruit of a playful life. Playful engagement with our domestic spaces will allow these changes to flourish in tandem with the redefinition of our domestic lives. Frank Lloyd Wright defined this as the 'fluid, elastic period of becoming...when possibilities are infinite'. ${ }^{64}$ This would ease the 'conflict that exists between the dynamic nature of people's lives and the homes in which they choose to reside'. ${ }^{65}$ In this sense, the very act of play is elemental to the act of being. The playful house becomes a tool for the personal expression and development of the inhabitant. Evidence of this is already realized in the work of certain architects and designers who have utilized various means to embed play into their design work. In the next chapter, some of these precedents will be investigated.

unplanned potential $\lrcorner$ Yyonne kearns 2012 


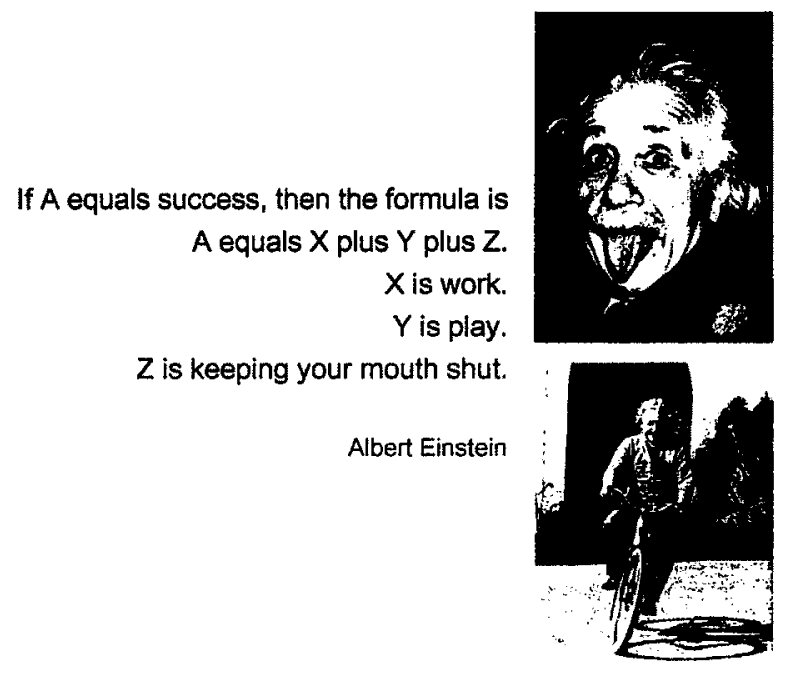

unplanned potential」 「yvonne kearns 2012 


\section{${ }^{3}$ praxis}

For the most part, houses throughout history and across cultures were arranged as a collection of rooms, each with assigned programmatic functions. ${ }^{66}$ Culture and economics often dictated the number of rooms, and the number of rooms determined to some degree how specialized each became. ${ }^{67}$ Frank Lloyd Wright is generally acknowledged as being responsible for breaking this mold, with the redefinition of the room through the birth of the open plan. ${ }^{68}$ Judy Attfield suggests that the open plan was a fundamental change in house design which 'embodied modernization', placing 'an emphasis on the functions and layout of the interior, eliminating walls to create a multipurpose "democratic" living space'. 69 The open plan, despite its advantages was not universally implemented as a house form. ${ }^{70}$ Unlike stylistic periods in the past, when housing styles were fairly uniform, the modern open house design was initially adopted only selectively. ${ }^{71}$ Furthermore, perhaps in an attempt to cultivate ties with the past, many of the open plan interiors were given exteriors reflecting various stylistic traditions, resulting in awkward combinations of mismatched styles. ${ }^{72}$

unplanned potential」 Tyvonne kearns 2012

31 
Eventually, the open plan gained popularity. Most new houses being build today are based on this arrangement, and exteriors have regained a level of uniformity. Below are a selection of plans that are currently available from various development corporations in the ottawa area, including Cardel Homes, Tamarak Homes and Ashcroft Homes.
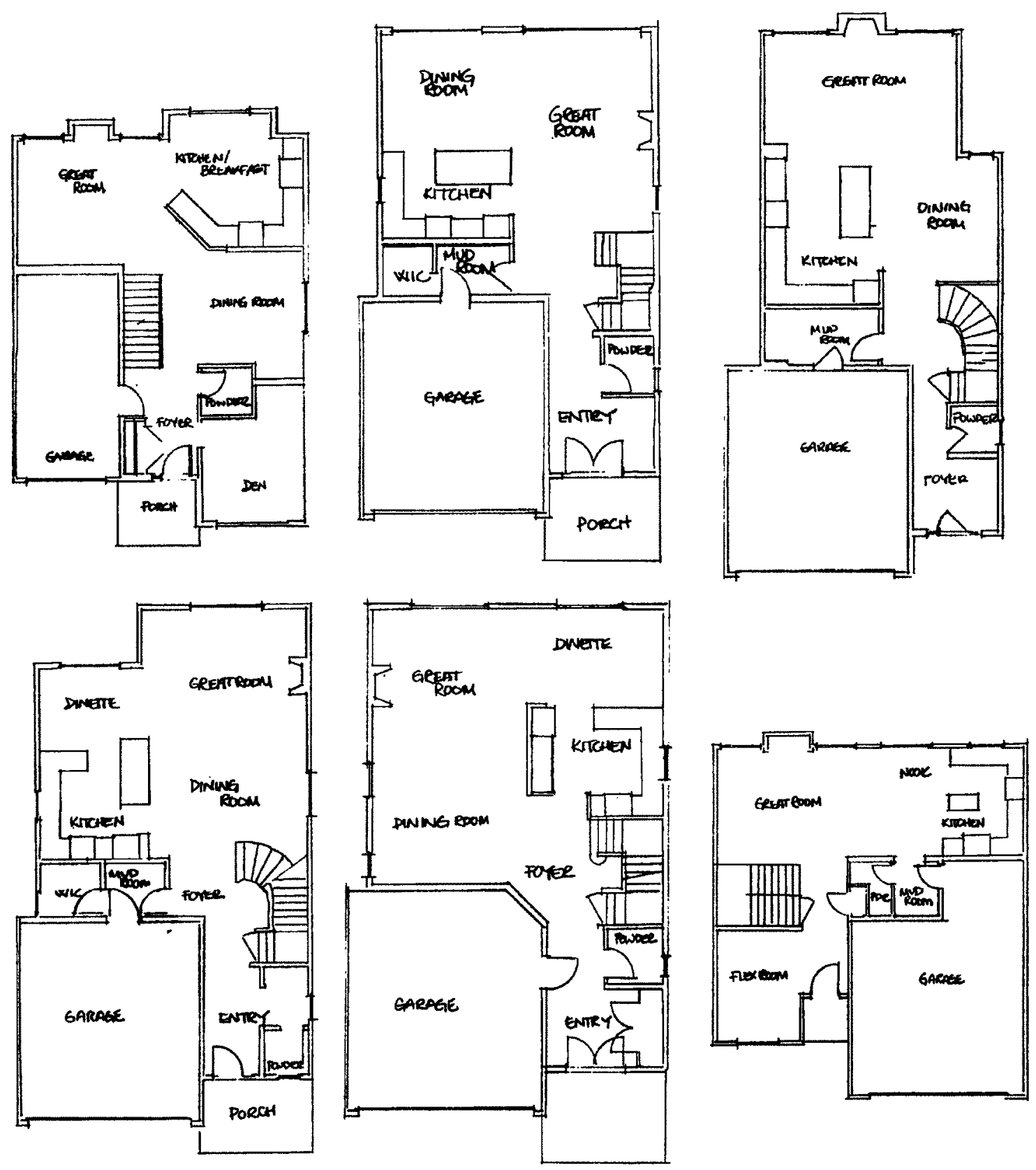
While the 'democracy' of the open plan is evident in these plans in the abandonment of the parlor, sitting room, living room and family room in favour of the great room, hierarchical value assignment has persisted. In these examples the 'great room' is given preference - it is usually the largest space (except the garage), is given the most fenestration, and is placed in a location central to the other frequently occupied spaces. Abutting the great room are the kitchen and the dining room. The cabinetry in the kitchen often leaves little or no room for windows. Space for eating is usually connected to both the great room and the kitchen. All of these living, cooking and dining spaces are situated at the back of the house. The front of the house, once home to the parlor and sitting room, is now given over to the garage, storage, circulation and laundry/bathroom facilities. These spaces, which can occupy up to half of the main floor area, provide a monolithic barrier between the living spaces of the house and the street.

Despite the apparent 'openness' of this pervasive pattern of house design, a significant level of constraint has been retained. Attfield suggests that 'the open plan is an insoluble contradiction since it is devised according to the very boundaries that control its openness by virtue of its place inside the confines of the enclosure of a building' ${ }^{73}$ These designs present a rather inflexible formal arrangement of space through both suggested and built fixed boundaries which compartmentalize programmatic activities. They can serve a directorial role for the encompassed narrative. They write the script, shape the activity, and provide the props. The arranged boundaries in almost all houses makes it impossible to make the morning coffee while engaging in conversation with a partner who is still in bed, because bounded spatial configurations dictates that coffee is made downstairs in a room specifically designed for food and drink preparation, while sleeping is assigned a space upstairs.

unplanned potential」 $\Gamma_{\text {Yvonne kearns } 2012}$ 
The doctrine that architecture can be conceived of as a great hollow sculpture or timeless unchanging form whose existence is an end in itself must be discarded.

Robert Sommer
Some houses might provide an outdoor hot tub, making communal bathing an acceptable activity. However, cultural norms dictate that this activity is inappropriate inside the house within the boundaries of a bathroom, where it would break the ingrained rules of privacy. The proliferation of these static boundaries can inhibit sociability since, in addition to the programmatic delineation, the participants in these activities are designated individual spaces. Adults might socialize in the great room while the children play or watch television in the den or the basement. Teenagers often spend vast amounts of time alone in their individual enclosed bedrooms. ${ }^{74}$

This is not to say that architectural boundaries must completely abandoned. The practice of architecture is, after all, the 'creation of boundaries out of otherwise boundless spaces, ${ }^{75}$. Partitions and thresholds are necessary for safety, comfort and privacy. What demands rethinking are both the nature and the proliferation of these boundaries. Rather than instituting boundaries which compartmentalize behavior and limit playful living, the design of adjustable parameters will leave room for the complexities of life to connect and flourish. The removal of select fixed boundaries and the introduction of malleability to the shape of domestic spaces will create a home that is in a constant state of becoming. The house, rather than existing as a static object, can become a participant in the continuous inventive dialogue between dweller and dwelling, disrupting the rut of routine and convention. The assumptions regarding the appropriate levels of privacy and sociability associated with various domestic activities can be reexamined. The dweller becomes free to play with new ways of living, allowing activities to overlap which were previously thought to be mutually exclusive. The opening up of these possibilities will generate an imaginative analysis of the various iterations the parameters of the home could make possible. Through the

unplanned potentials $\Gamma_{\text {yvonne kearns } 2012}$ 
Form is the end, death. Form-giving is life.

Paul Klee
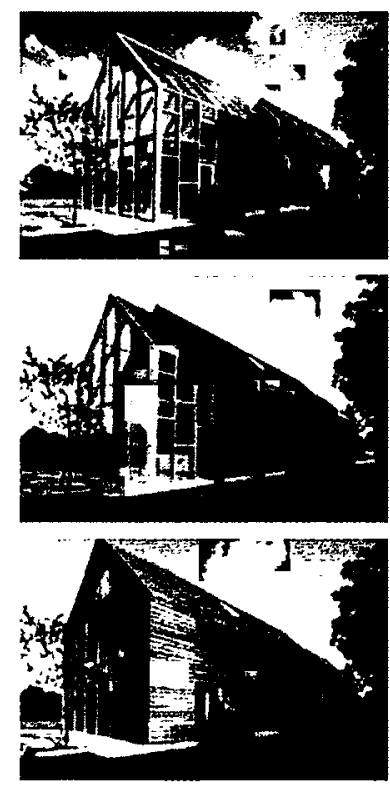

Sliding House

East Anglia GB dRMM Architects selective deconstruction of boundaries, domestic space loses its prescriptive rigidity. It no longer dictates, but rather invites a continuous redefinition and evolution of the architectural space. By the very nature of their pliancy, deconstructed boundaries can challenge convention and urge us to reconsider how we practice everyday life. They can be instrumental in our process of Heidegger's notion of 'learning to dwell'76. By loosening or eradicating programmatic separation, malleable boundaries will nurture the playful layering of narrative, allowing the rich ambiguities of domestic life to thrive. This might permit us to see our world through perspectives we might otherwise have never imagined, broadening our scope and cultivating our imagination.

The traditional formal exterior structure is a form of static boundary that is awaiting transformation. The Sliding House in East Anglia, Great Britain by dRMM Architects is a beautiful realization of this potential. The house has a mobile monolithic envelope which slides along the length of the structure, transforming the nature and experience of the interior spaces. Various openings and voids in the inner volume line up with corresponding openings in the sleeve as it moves along the track, alternatively blocking or admitting light. This design presents a distinctive and unusual solution to issues of privacy and light control, and allows the inhabitant a certain amount of control over the formal qualities of the house. Sliding House demonstrates the effect of constructing multiple architectural potentials through the use of unfixed boundaries. The beauty and inimitability of the movable exterior entices the dweller to engage with the form of the dwelling.

Chicken Point Cabin, designed by Tom Kundig, has an unfixed exterior boundary on a smaller scale. The rear glass wall of the house rests on a pivot, and can be swung into a

unplanned potential」 「yvonne kearns 2012 


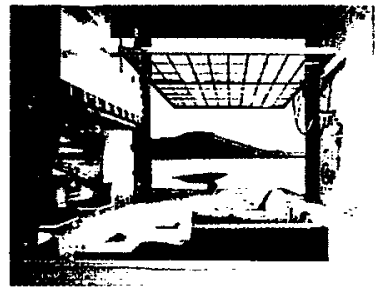

Tom Kundig Chicken Point Cabin horizontal position, opening up the interior of the house to the outdoors. The level of engagement facilitated in this case is furthered by the nature of the interface between the dweller and the mutable boundary. Rather than driving the motion through a motor, as is the case in the sliding House, Kundig engages the dweller's physical body to initiate and power the motion. Clever engineering allows the user to manipulate the large window - 20 by 30 feet - through a wheel crank that a child can easily manage. The resultant connection with the dwelling is visceral and tangible, and enriches the play experience. The moveable boundary brings dynamism to the space and also incorporates playful engagement of the body. The tactile experience of bodily motion is converted into the transformation of the architectural form.

Both the Sliding House and Chicken Point Cabin provide benefits beyond a playful engagement with the changeable form through reducing the barrier to the outdoors. A view of nature as well as the opportunity for physical engagement with it are beneficial both physically and emotionally, and are thus a significant ingredient in the playful life. These types of penetrable exterior thresholds are not the norm. While levels of fenestration have increased in recent years, the fixed nature of these boundaries suggests a passive relationship to the outdoors. Living can occur entirely indoors while the outdoors is experienced through disengaged observation, being seen as an aesthetic object rather than habitable space. Further, the character and content of outdoor spaces is at times given little thought. In new housing developments trees are indiscriminately removed for the purpose of construction expediency, leaving a desolate swath of barren housing.

Despite a wet and rainy climate, housing in the Netherlands addresses the relationship between indoors and outdoors in a

unplanned potentials $\Gamma_{\text {yvonne kearns } 2012}$ 


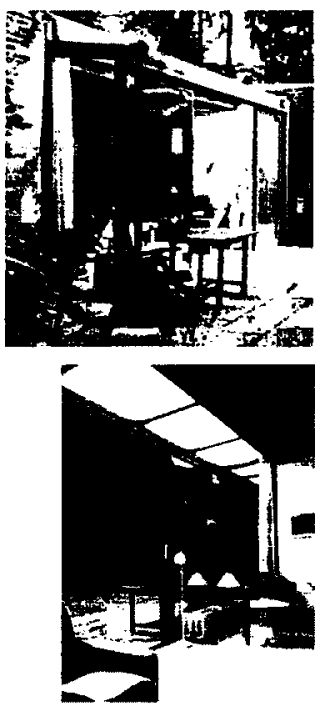

van der Ros House

The Netherlands less confining manner than is common in North America. An example of this can be found in a house belonging to my extended family in Son, Noord Brabant. In this house a connection between indoors and out is established by the use of large amounts of fenestration in the threshold between the two. The fenestration is not fixed, but rather can be folded aside, removing the barrier to the outdoor space and making its inhabitation much more enticing. The natural flow of activities between the two spaces serves as a catalyst for the imagination and breeds new ideas about playful living. The porosity of the typical Dutch threshold also advances sociability. The Dutch don't seem to have the anxious need for privacy that is evident in North America. Windows are usually large and uncovered. An evening stroll along a resident street will allow frequent glimpses into the lit houses being passed. The inhabitant of the house extends an invitation for a connective relationship by virtue of their transparency. The one simple glance of the passer-by completes the connection, and sociability is established. This type of visual openness contributes to the atmosphere of affability and warmth and promotes a community of connected individualities, rather than an apparent collective of hermetic isolations. While this level of transparency might be uncomfortable for many North Americans, it does demonstrate the impact that visual openness can have on social dynamics.

Unfixed boundaries can be employed in places other than the building threshold. A flexible interior arrangement of space is put to good use in the Suitcase House by Gary Chang in Hong Kong. It is a box-like house with what appears to be a single open interior space. The floor, however, conceals containers beneath it that accommodate the functionality of the house. Flaps integrated into the floor open these spaces up, which are entered by descending a few steps. In this way the house has multiple possible configurations based on the

unplanned potential」「yvonne kearns 2012 
need for open space or privacy, room for many or room for one. The house provides much more than a single moveable boundary; it allows the interior space to be rearranged in multiple dynamic ways.

Another method by which architecture can facilitate playful engagement is through a creative exploration of materiality. David Pye suggests that,

'the properties of materials are objective and measurable. They are out there. The qualities on the other hand are subjective: they are in here: in our heads. They are ideas of ours. They are part of that private view of the world which artists each have within them.'

Materials are not merely passive ingredients to be manipulated in the creation of a specific form. A material has qualities and values of its own, carrying meaning which can be translated and augmented through combination with other materials. Tim Ingold suggests that 'what materials seek to overcome in their rhetoric is the lingering influence of a way of thinking about things, and about how they are made and used'. 77 Materials can be freed from their defined purpose to exists through the qualities of their materiality. When these qualities are celebrated and pushed to the limits of their potential, they begin to participate in the semiotics of dwelling.

The qualities of fabric are literally stretched to the limits of their potential in the BMW Gina Light Visionary model. Rather than presenting the rigid metal frame common to most cars, this concept car has a seamless textile fabric skin that encompasses a transformable metal and carbon fiber frame. The result is a shape-shifting car that transforms at the will of the driver. The car begs to be touched and engaged with. It also shatters conventional ideas about 'carness'. BMW gave their design team latitude to play with

unplanned potential」 $\Gamma_{\text {Yvonne kearns } 2012}$ 


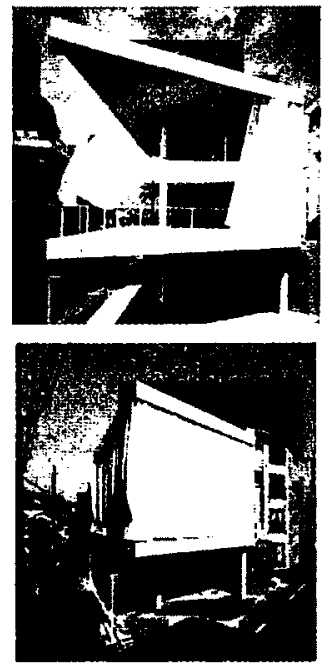

Shigeru Ban Curtain Wall House materials in this way in order to 'push the boundaries of appearance and materials' ${ }^{78}$

The Curtain Wall House by Shigeru Ban employs both an innovative use of materials and the establishment of an unfixed exterior boundary. The envelope of the house is a massive curtain which, based on where it is positioned, renders the adjoining space inside or outside. Ban suggests that the interior and exterior spaces are continuous and the intermediate domain shifts. ${ }^{79}$ He terms the resultant indeterminacy of the space the "universal floor". ${ }^{80}$ Ban has placed the vast swaths of fabric outside of their usual context. He plays with the meaning of 'wall' and 'threshold' by thwarting our expectations of the form these elements ought to take. The exterior boundary of the house, usually solid and immoveable, exhibits a pliancy and effervescence; it effectively requires a bodily embrace to move aside. Ban has turned the customary solid and static nature of the traditional exterior wall on its head. He has allowed it to breathe and given it the ability to absorb the surrounding air currents into its form. He makes it impossible to occupy the house without having some awareness of what is occurring beyond the threshold.

Natural materials are at times utilized in ways that not only ignore their qualities, but actually supress and conceal them. They are cut and molded and treated with chemicals until they no longer display their original intrinsic characteristics. The warmth and softness of wood is at times hidden beneath layers of lacquer. It is transformed into flooring that is a glossy mirror which has left any sense of 'woodness' far behind. Leather, in its natural setting, is exposed to the elements, covered in mud and beaten by the rain. Through extensive processing, it is treated and dyed and used, among other things, to make furniture. The final product, while retaining some of leather's initial

unplanned potentialı. $r_{\text {yvonne kearns } 2012}$ 


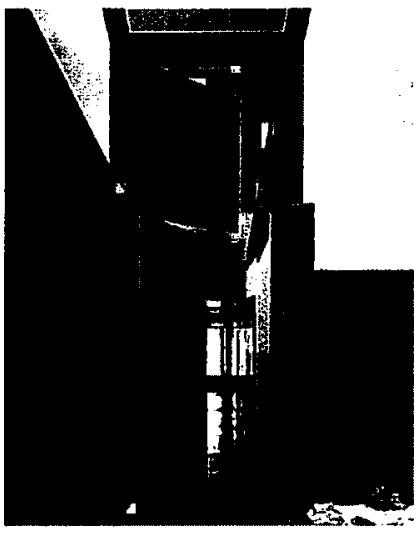

Montecito Residence Olson Kundig Architects

Far from being the inanimate stuff typically envisioned by modern thought, materials are active constituents of a world-in-formation.

Tim Ingold robustness, must be kept out of the sun for fear of fading, and rubbed with oil to prevent cracking. Its materiality bears little resemblance to its original condition.

Similarly, the materiality of our houses can resist tactile interaction because they have been elevated to the status of a sacred or precious object. Behaviour in the home can be restricted for fear of scratching the floor or denting the meticulously painted walls. Some of these materials are designed to be tread lightly upon, or to not be touched at all. In contrast to this, the steel envelope of the Montecito Residence by 0lson Kundig Architects has been left untreated. The inherent characteristics of the steel are celebrated. It is left to oxidize and rust over time, giving the building envelope a warmth that is in contrast with the usual smooth industrial appearance of steel. The beauty of the oxidization process is further emphasized by its juxtaposition with the cool glass fenestration. The celebration of steel's ability to weather and corrode, allows it to lose its 'untouchability'.

Instances of architecture that incorporates play do exist. Unfixed boundaries, both exterior and interior, have found their way into the architectural lexicon. Architectural variability is being incorporated into design for purposes of practicality or economy, and play can often emerge as an invaluable by-product. Materials have been played with and taken out of context, their qualities have been accentuated and their limits have been challenged. In many cases, the architect has often been playful in the design process, and the resultant spaces are unique and imaginative. Does this level of playfulness in architecture have the potential to be furthered? Some architectural elements might further cultivate play when they gain a certain amount of ambiguity. In recalling Julie's plastic house, we can observe that a factor in its resistance to intervention is its designated

unplanned potential」 $r_{\text {yvonne kearns } 2012}$ 
purpose. Manipulation of the object would interfere with its perceived value, as its value is associated with its intended use rather than the cost of the materials with which it is constructed. Conversely, Julie's cardboard box facilitates play through the ambiguity of its purpose, and its perceived lack of monetary value. Its play potential is embodied in its materiality rather than its form, liberating the form to be freely altered. When architectural elements are designed with some level of ambiguity, the user's imagination is aroused to engage with the object and participate in the development of its definition and purpose.

unplanned potential」 「.. Yvonne kearns 2012 


\section{${ }^{4}$ housing play}

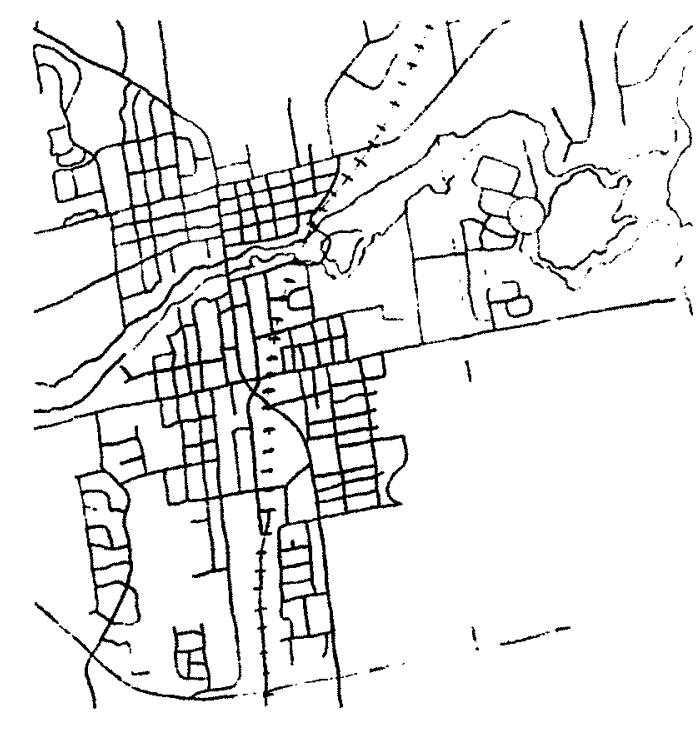

The site for this thesis project is a lot in a subdivision that is currently under construction in Carleton Place, a town to the west of Ottawa, Ontario. Carleton Place is a picturesque town with a history of lumber milling, and the lot, shown in yellow to the left, backs onto the Mississippi river. Further details regarding the town and the lot can be found in appendix one.

The aim of this thesis project is to perpetuate play through the design of potential playspace in the form of domestic architecture. The objective is to situate the process of spatial design well beyond the drawing board, to allow a continuous metamorphosis the domestic environment throughout the its lifespan. The realization of this theory and its application to architecture began with various material and formal investigations. The design challenge was approached by playing with these materials and forms, seeking to discover their changeability, their embedded meanings, and their various potentialities. These playful inquiries facilitated an understanding of the ways in which material, form and changeability can augment play.

In an exploration of the ways in which boundaries might be unfixed, a malleable segmented shape was inlaid in a flat

unplanned potential」. 「Yvonne kearns 2012 

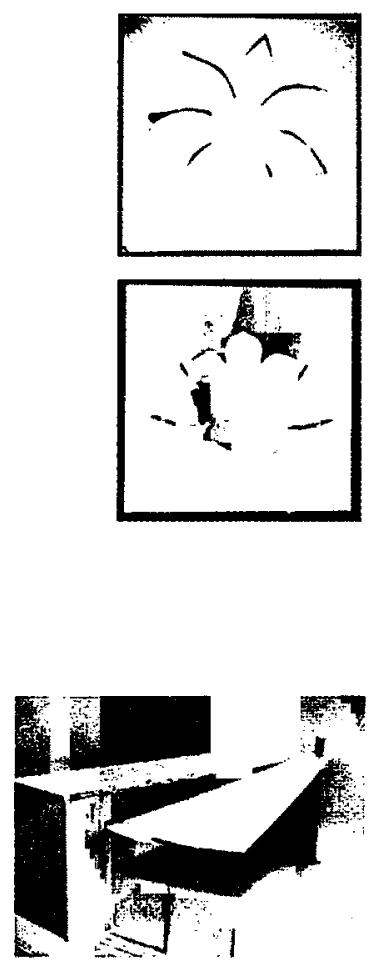

surface. The segments could be curved up to form the boundaries of a three-dimensional volume. The meaning of the moveable segments was transformable, being derived through their relative position at any given moment - the 'floor' could be curved up to become a 'wall', and the 'wall' could be lain flat to become a 'floor'.

This idea was translated from the initial conceptual model to the exterior boundaries of a house. In order to take advantage of the natural beauty of the river and greenery adjacent to the site, the rear of the house was the focus for the implementation of an exterior moveable boundary. Various options were investigated to address the means by which the wall could be unfixed. The mechanisms examined were successful in opening the interior of the house to the outdoors. However, it became clear that the placement of the glass wall in its open position, although less intrusive, still provided a barrier to sound, wind and potential social connections.

The solution to this encumbrance was to design the rear wall to be raised completely out of the way in much the same way that a typical garage door is raised. Once elevated, the rear wall of the house remains out of site, and the indoor and outdoor spaces are connected and unified. The interiorexterior spatial connection is further accentuated through the use of a single flooring material of poured concrete which spans the entire space. The concrete floor provides a robust and fairly indestructible surface on which to play. A similar approach was implemented at the front of the house. The main entry, rather than being the traditional hinged door, is a large glass aperture which can be slid to the side, leaving the entry completely free from obstruction. A connection to the street is more firmly established by a further continuance of the polished concrete flooring material. The outdoor space at the front is generous, and

unplanned potential」 $\Gamma_{\text {yvonne kearns } 2012}$ 
wide shallow steps are provided to descend to the street level. The unfixed boundaries of the envelope cultivate play. The natural environment at the rear and the neighbourhood and street at the front become extensions of the interior playspace. In order to further the potential for sociability, the roof of the partially subterranean garage is a garden. This garden in on the south side of the house, adjacent to a pre-existent foot path that connects the street to the river. The exterior of the house is clad in wood, which serves as a perceptual connection between the house and the core of town, and as an mnemonic device for town's history of lumber milling. Despite the location of the house in a housing development that is detached from the core of the town, it gains some continuity and coherence with the town as a whole.

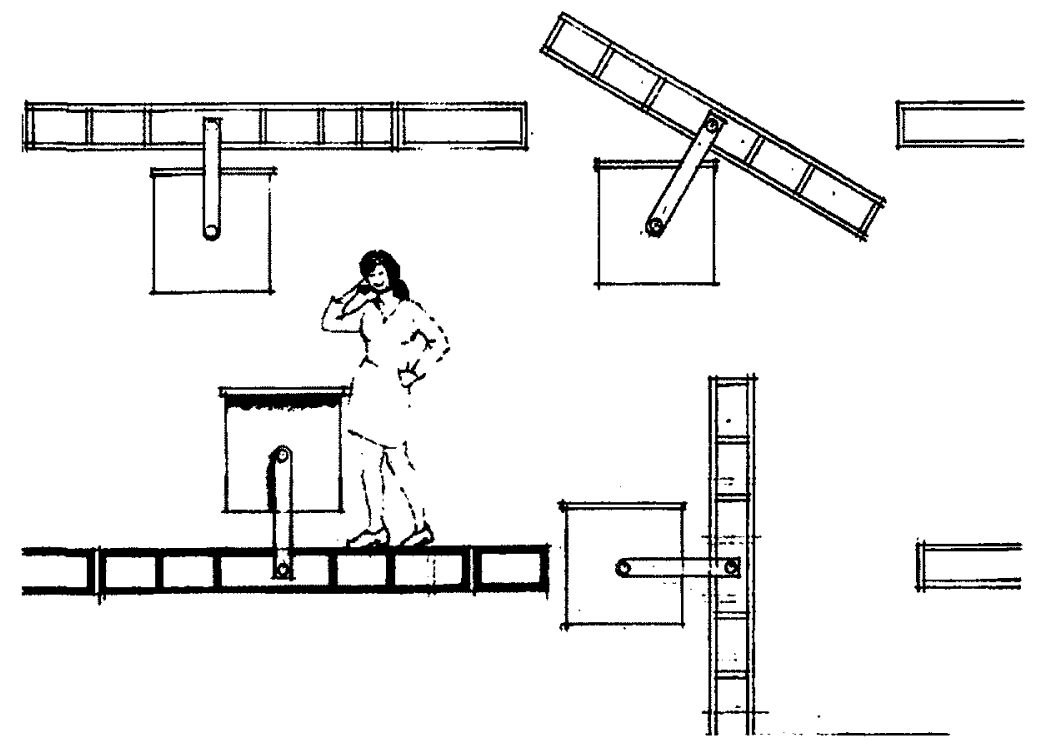

The design process subsequently led to an investigation of the possible malleability of the interior spaces of the house. An attempt was made to maximize the openness of the main living space by removing all but the necessary boundaries. Initially, a playful approach to the traditional fixed nature of the practical amenities of a house resulted

unplanned potential」. Tyvonne kearns 2012 
in a series of pivoting volumes. These volumes contained the cooking facilities, bathroom facilities, and storage facilities. A counterweighted system was conceived that would allow these volumes to be rotated to rest beneath the floor. In this way, the main living space had the potential to be completely unobstructed, providing a large open playspace. Upon consideration, the pivoting volumes were revealed to be somewhat cumbersome. While the idea might be playful and unique, the reality of daily living in a house that required significant effort to access the cooking facilities was less than optimally playful.

The final formal design of the house is patterned on two arcs which sweep through the site. They are a conceptual representation of the way in which play can intersect and overlap with the various elements of everyday life. The arcs contain all of the circulation and functional facilities of the house. They extend past the envelope to provide shape and form to some of the exterior components of the house, in particular the front and rear outdoor living spaces. The kitchen is positioned within one of the arcs towards the front of the main living area. A sliding wall is provided, with tracks that enable it to be positioned on either side of the cooking space, or to be tucked away out of sight. The sliding wall provides three possible iterations:

- The wall can be completely slid out of the way. The cooking facilities protrude into a large single-volume living space.

- The wall can be slid to the front of the counter, making the kitchen a part of the main living space, and creating a smaller private space on the other side of the wall that could be used for an intimate dining experience or for other activities that require a certain amount of privacy.

unplanned potential」 「yvonne kearns 2012 


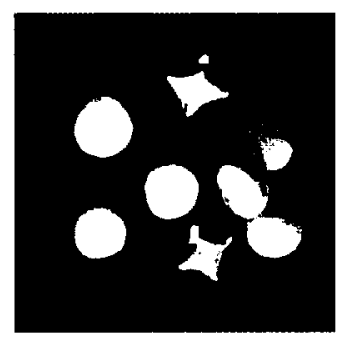

- The wall can be situated at back of the counter. This positions the kitchen within the smaller space at the front, providing a potential combined cooking and eating space, and placing it out of sight of the larger main living space.

Transformable boundaries were also utilized in the design of the upper floor. This floor contains a bathroom, including a shower stall that can, through a counterweighted pulley system, be pushed out of the interior volume of the house to the outside. The shower system challenges conventional ideas regarding bathing, privacy and enclosure. Beyond the circulation arc, the rest of the upper floor is entirely flexible. A railing system is fashioned which follows the arc of the upstairs circulations. This system enables floor and wall panels to be slid into place or out of the way at the will of the dweller. There is provision for a total of 34 square meters of floor space on the upper level, which can be divided into as many as four rooms. The individual rooms can be configured as loft spaces, with a simple railing providing the boundaries, as private rooms with walls on four sides, or as a combination of these two options. A high degree of malleability is thus established on the upper floor, resulting in a house that can be changed to suit the needs of a growing and evolving family unit. Rooms can be added or collapsed to coincide with changes in the family situation.

As a further investigation into malleability various materials were playfully shaped and manipulated. The first was a series of molded volumetric shapes which could be arranged to create a single volume. The individual pieces in this study triggered the imagination due to their vague resemblance of other familiar objects, and creativity was implemented to discover unique ways of fitting them together. Subsequent exploration involved pieces of laminated wood fashioned into an assortment of curved and flat surfaces. The

unplanned potential」 $\Gamma_{\text {yvonne kearns } 2012}$ 

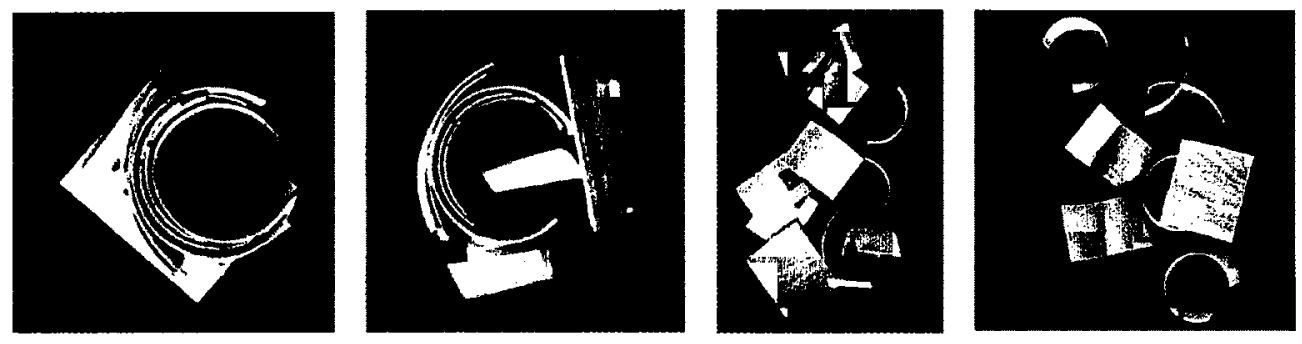

qualities of wood were investigated as it was twisted and glued into curvilinear shapes. These objects presented opportunities for play similar to those provided by the previous investigation, but furthered the capacity for creative intervention through their potential for assemblage. New voids and forms were produced with each unique combination, which in turn altered the object's potential meaning.

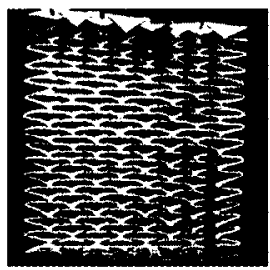

An extensive study was conducted into paper folding, generating a wide variety of multi-dimensional forms. A beauty was uncovered which is inherent in the creation of complicated articulated objects through the manipulation of a simple sheet of paper. The scope for play with this medium

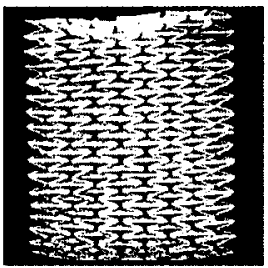
appeared to be endless. Organic creatures were generated which, once formed, continued to submit themselves to further manipulation. The folding process was beautifully open ended and recursive; the folding could stop at any moment in time, resulting in a particular entity, or it could continue, leading the player on into unanticipated territory. The entire investigation into folding revealed an ambiguity which augmented the opportunity for play. Paper is an enticing tool for play because folding requires the player to work creatively within the bounds of its material qualities and limitations. Furthermore, the meaning of 'paper' becomes ambiguous through the folding process, with its final form and definition being left to the creativity of the player. Paper folding laid the groundwork for the final incorporation of malleability into the design of the house.

unplanned potential」 $\Gamma_{\text {yvonne kearns } 2012}$ 

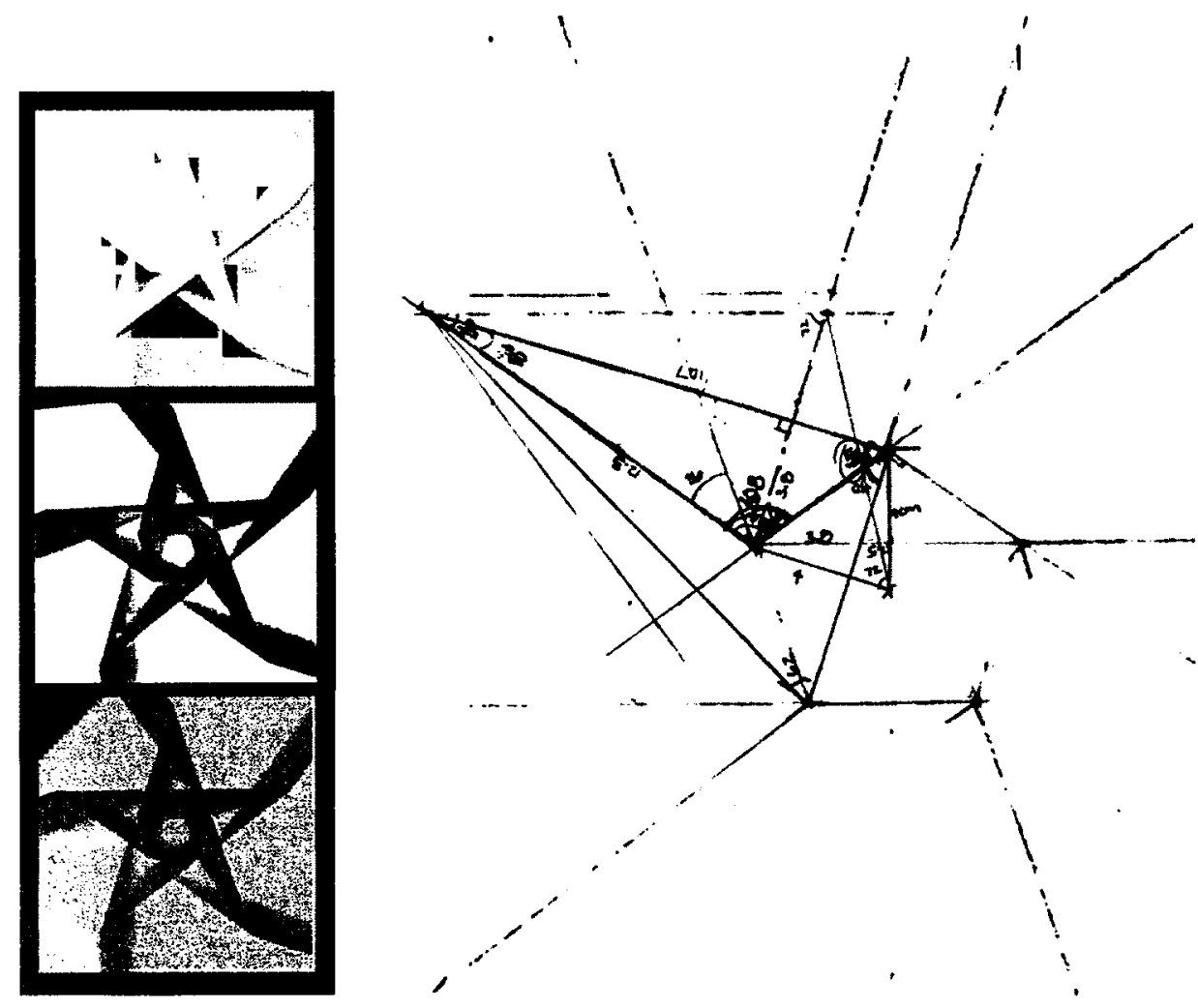

The final changeable element in the interior of the house is realized in an articulated wall on the main floor. It presents the dweller with a series of panels which, when not in use, can be lowered into a slot in the floor. The function of the panels has been allowed some ambiguity. On initial viewing, they appear to be nothing more than optional wall panels. A closer look, however, will reveal that their form is changeable. They can be removed from the track which houses them, bent into various shapes, and attached and combined with each other panels to generate new forms. A small-scale model of this 'wall' system was presented to various individuals for objective input, and their creative manipulations of it were documented. They were bent and arranged to form little rooms, seating surfaces, storage containers, privacy walls, tunnels and climbing structures. It is my hope that these formal suggestions are merely a

unplanned potential」 $\Gamma_{\text {yvonne kearns } 2012}$ 
beginning, and that if realized, this design would facilitate other iterations that haven't yet been imagined.

unplanned potential」 $\Gamma_{\text {yvonne kearns } 2012}$ 


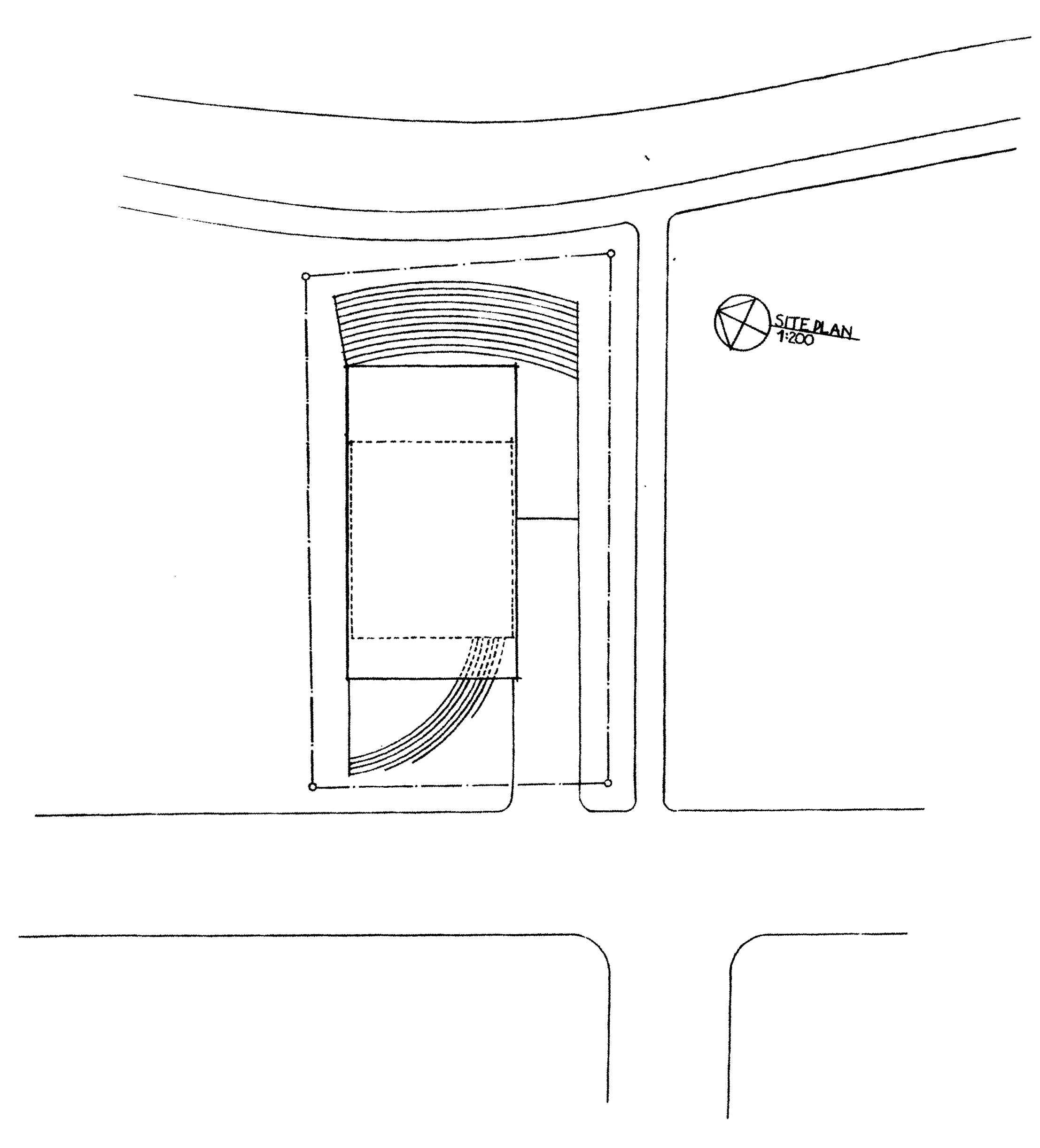




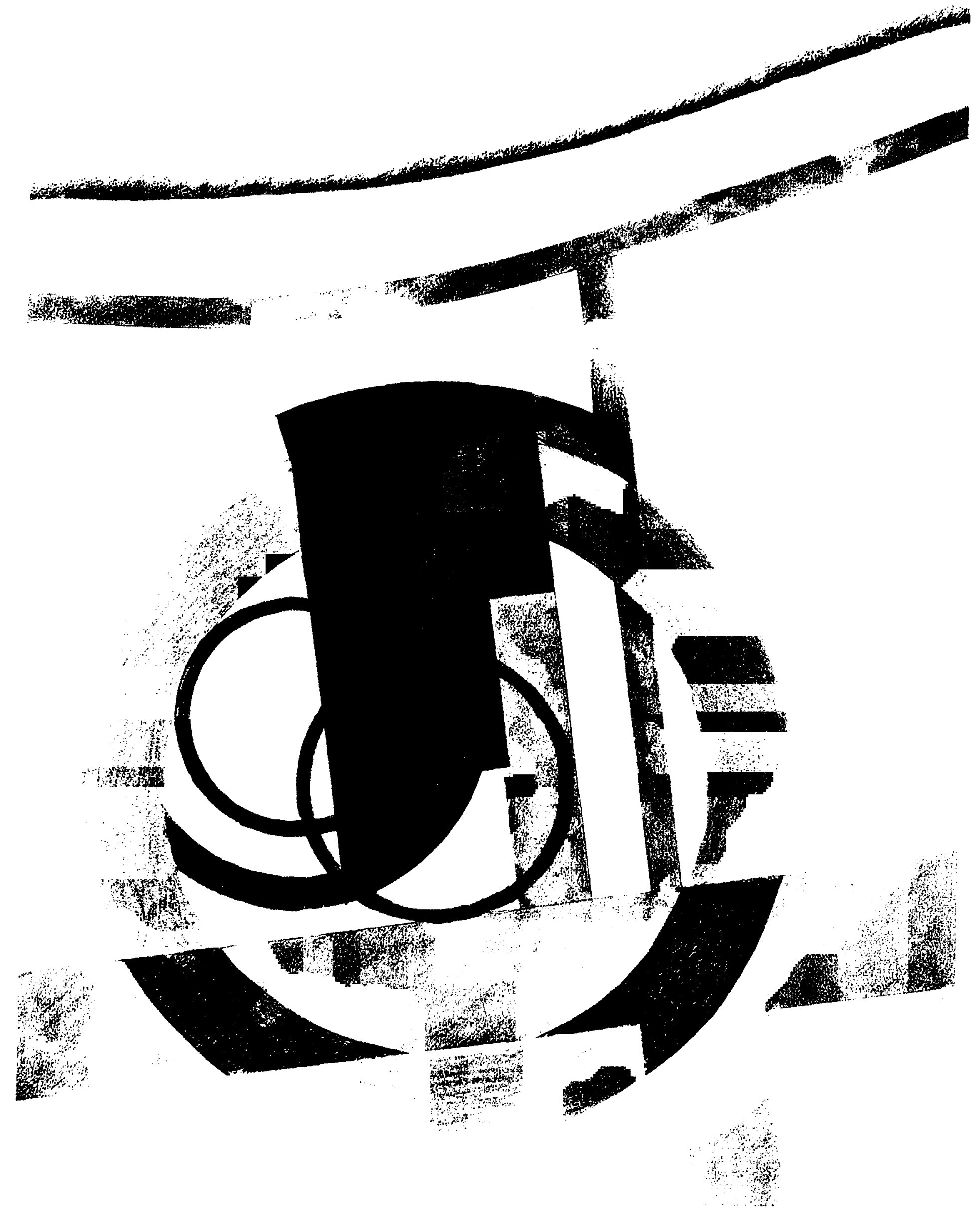




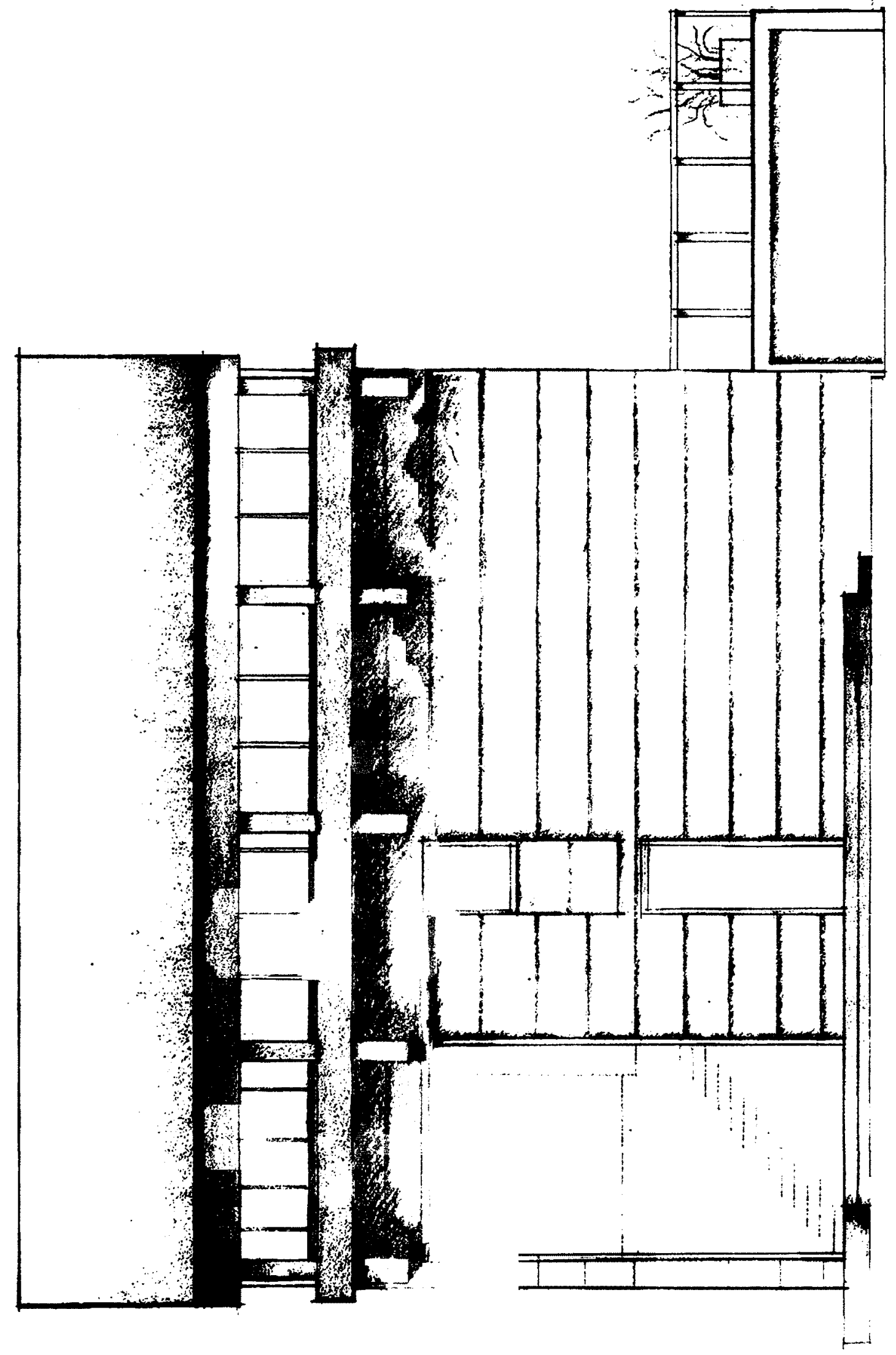



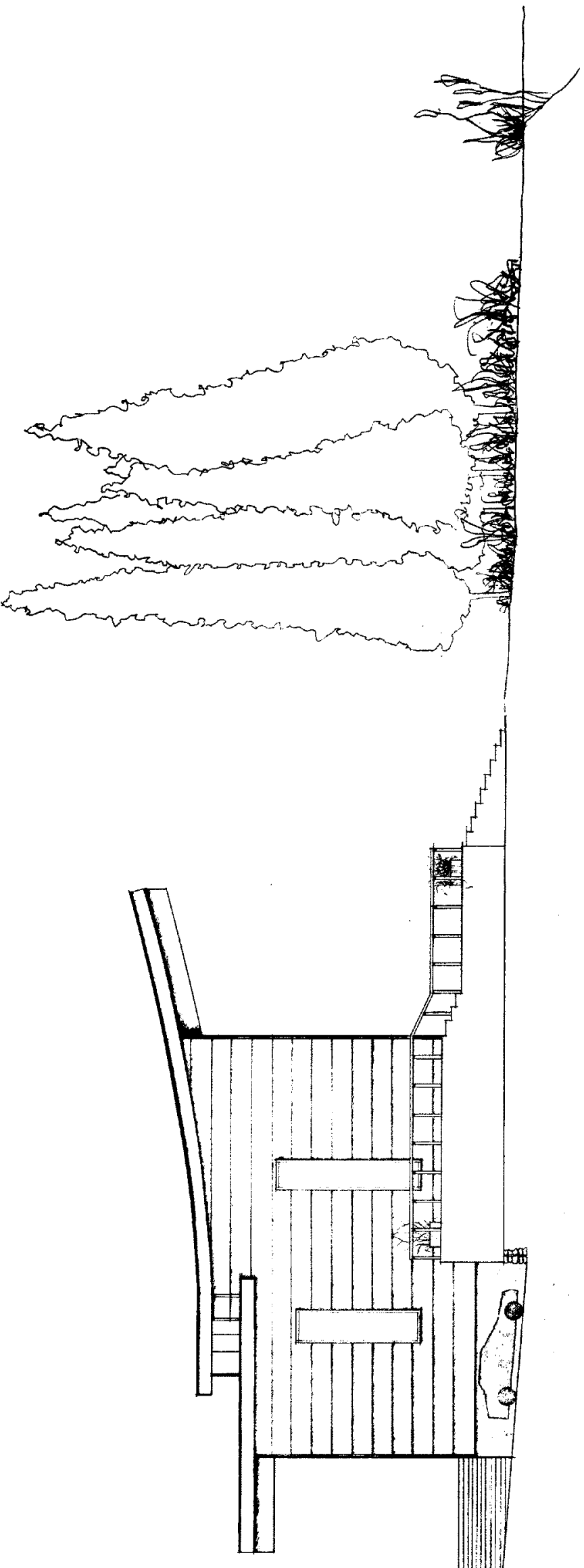


\section{LAYERED AXONOMETRIC DRAWING}

Please go to page 59 and unfold the base drawing.

Page 55 can be unfolded to provide view of the exterior.

Three scenes can be viewed by unfolding pages 56,57 and 58. The upper portion and right portion of page 59 can be folded over the base drawing and any particular scene to provide views of the rear window wall in its down or retracted position within that scene.

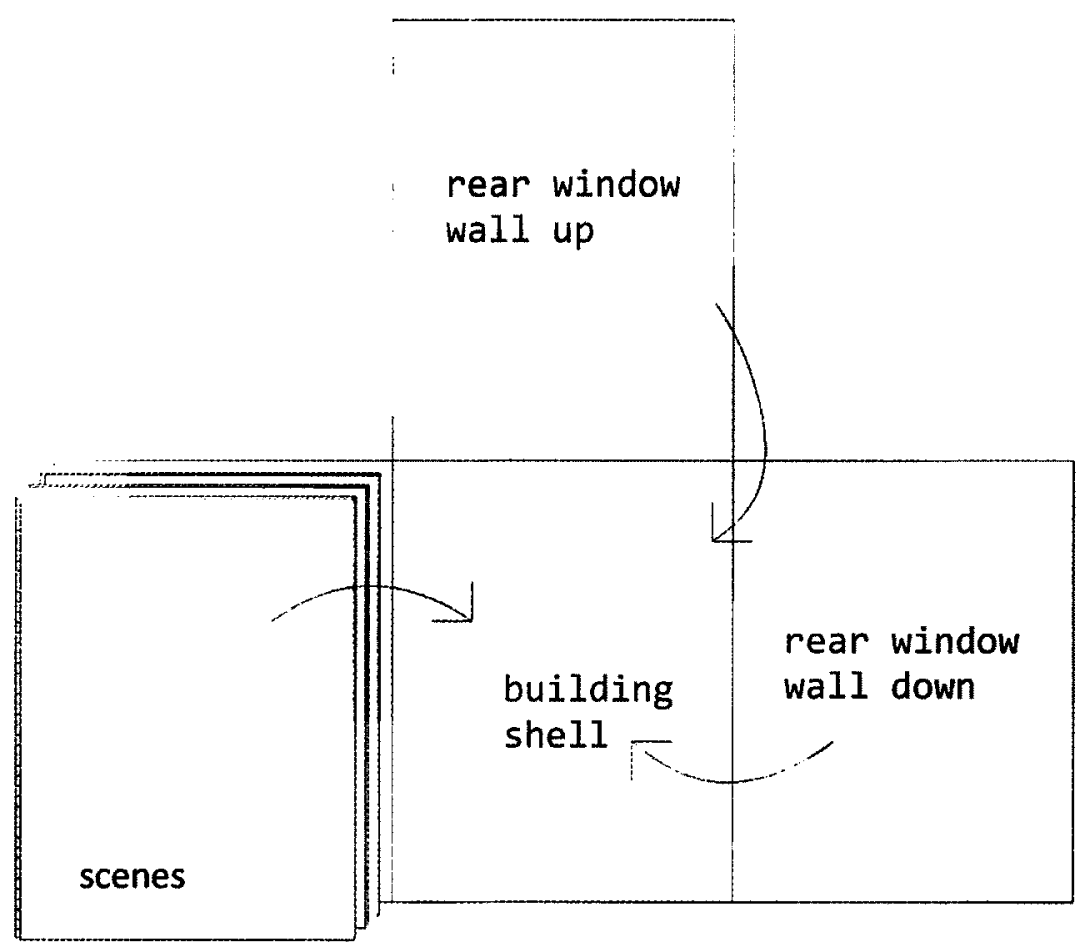

unplanned potential」 「yvonne kearns 2012

54 
<smiles>C1CCC2(CC1)CCCC2</smiles> 


\section{ACT 2 \\ SCENE 1}

Robert has pulled 4 upper level floor panels across to the end of the railing, creating a loft studio for himself.

Robert is working there now, writing his latest spy thriller.

Robert's friend, Doug, has come over for a visit. Doug has pulled the kitchen wall out to create an enclosed cooking and dining space.

Robert is preparing food for the dinner part that the two are planning for a group of

friends, to take place later in the evening.

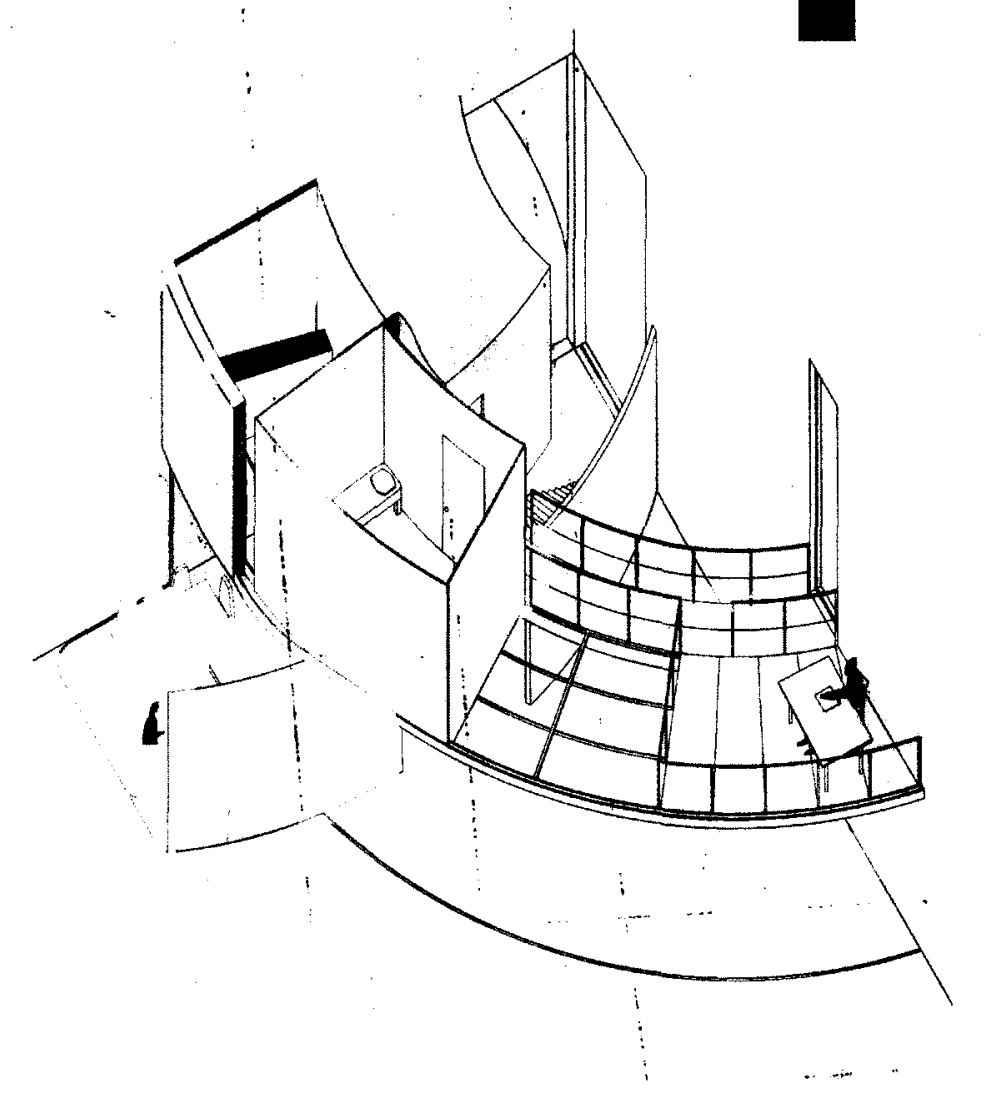




\section{ACT 2}

SCENE $\cdot 2$

Lara has pulled across the wall and floor panels to create three bedrooms on the upper level for her and her children.

The kitchen wall has been tucked away.

Her childred have some friends over, and she is busy cooking them a snack while they play.

Adam has rolled one of the wall panels into a tube, and he's having fun crawling through

it.

Aidan and Ramajan are playing catch.

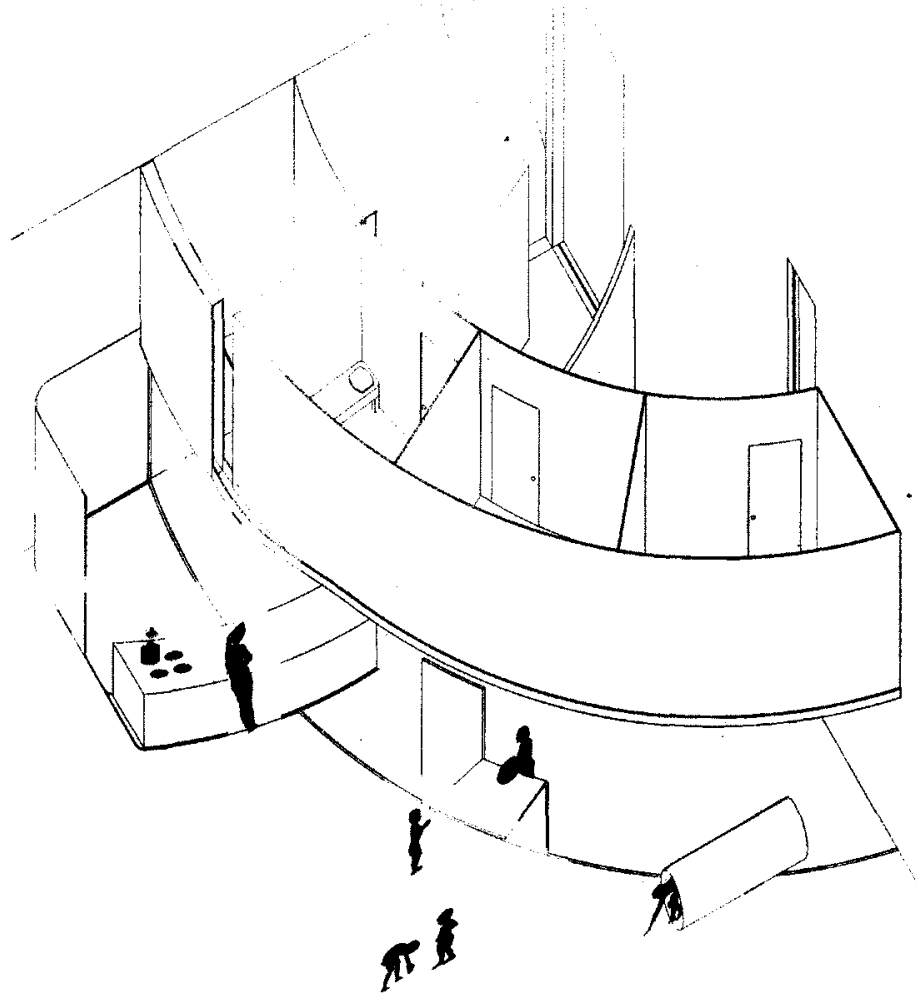


ACT 2

SCENE 3

Jim has pulled 4 upper level floor panels across to the end of the railing, creating a loft sleeping space for himself.

Jim is having a few friends over. The kitchen wall has been pulled across, leaving room for food to be laid out for his guests, and providing a small intimate space for conversation. The openness of the main floor leaves plenty of room for people to gather and socialize, and also permits some dancing or a game of soccer later in the evening.

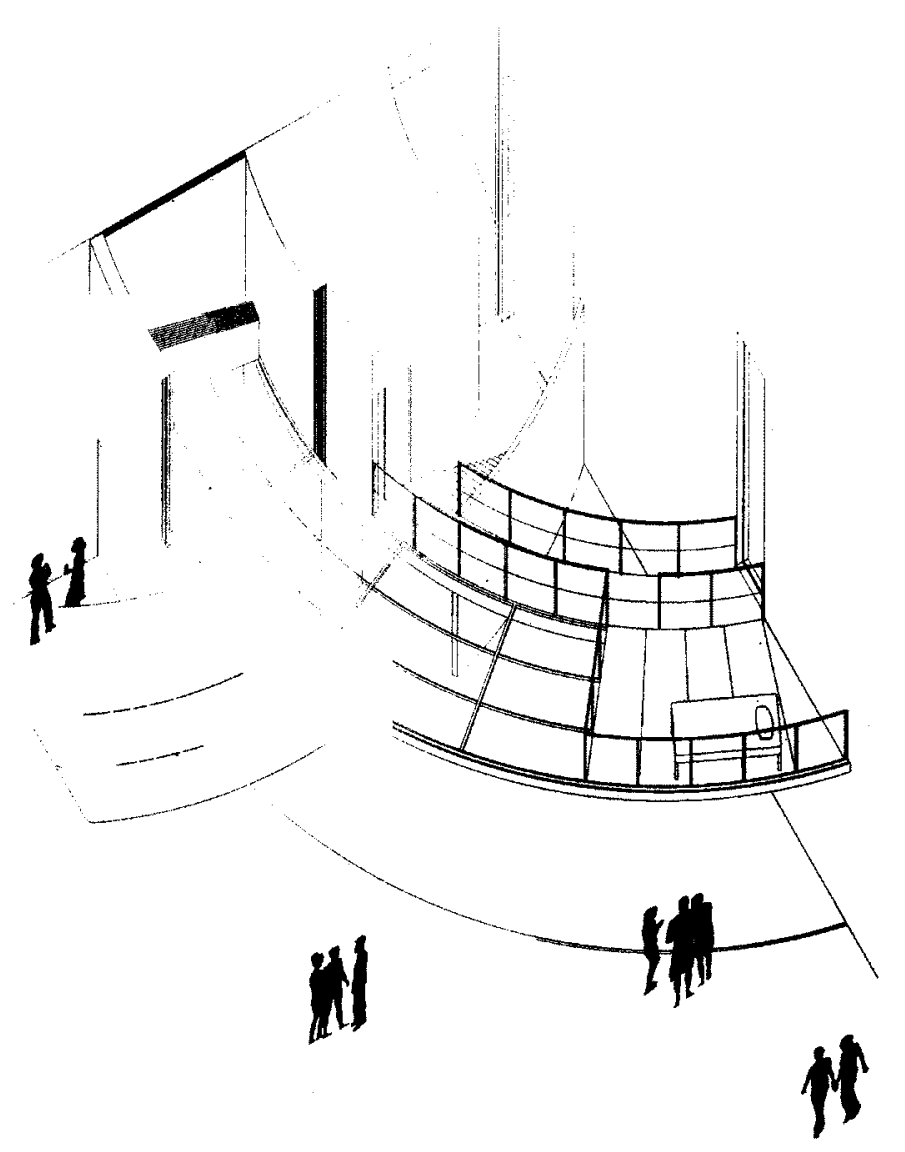

scale

$1: 125$ 



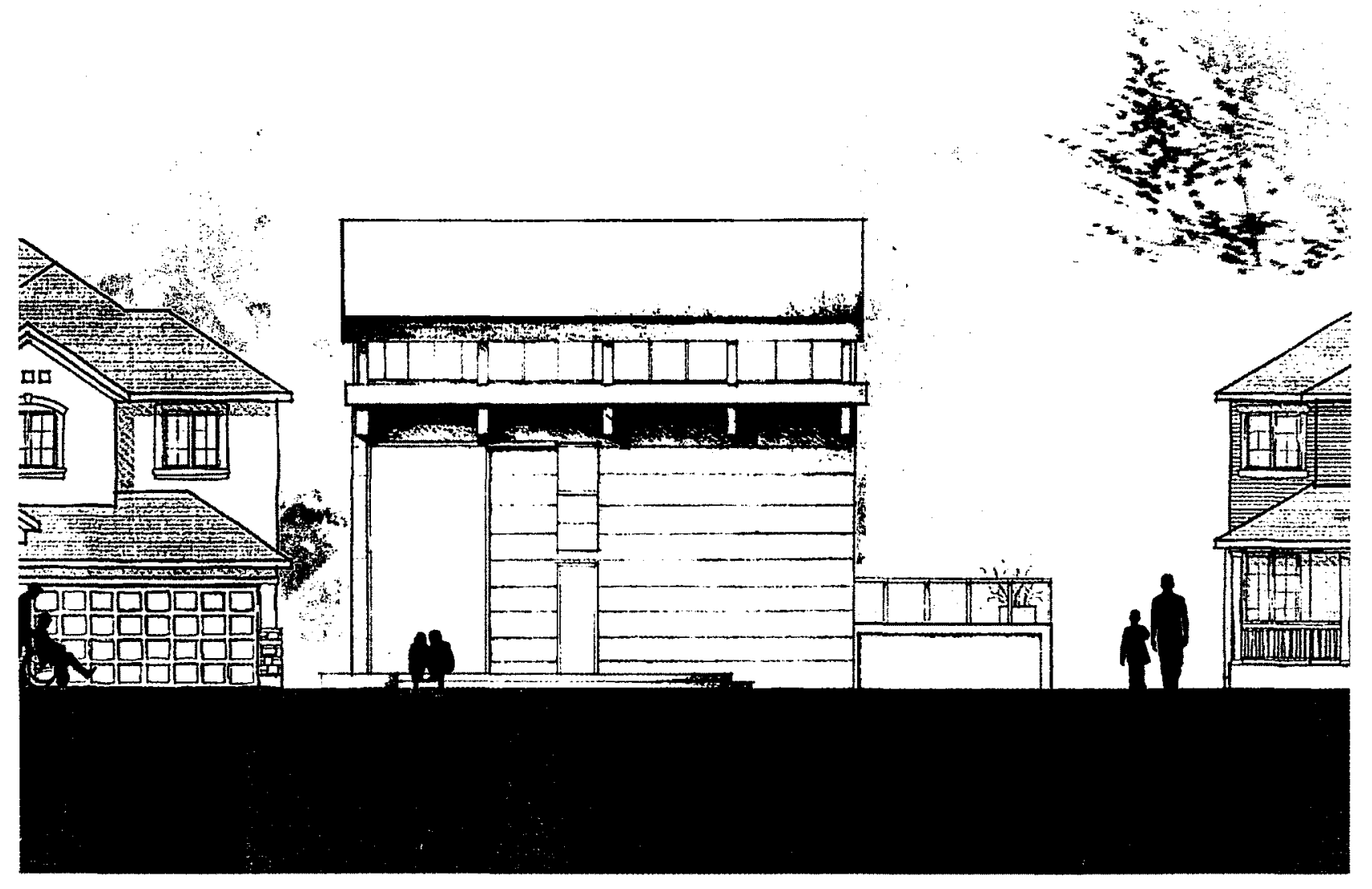

unplanned potential」 $「$ Yvonne kearns 2012 


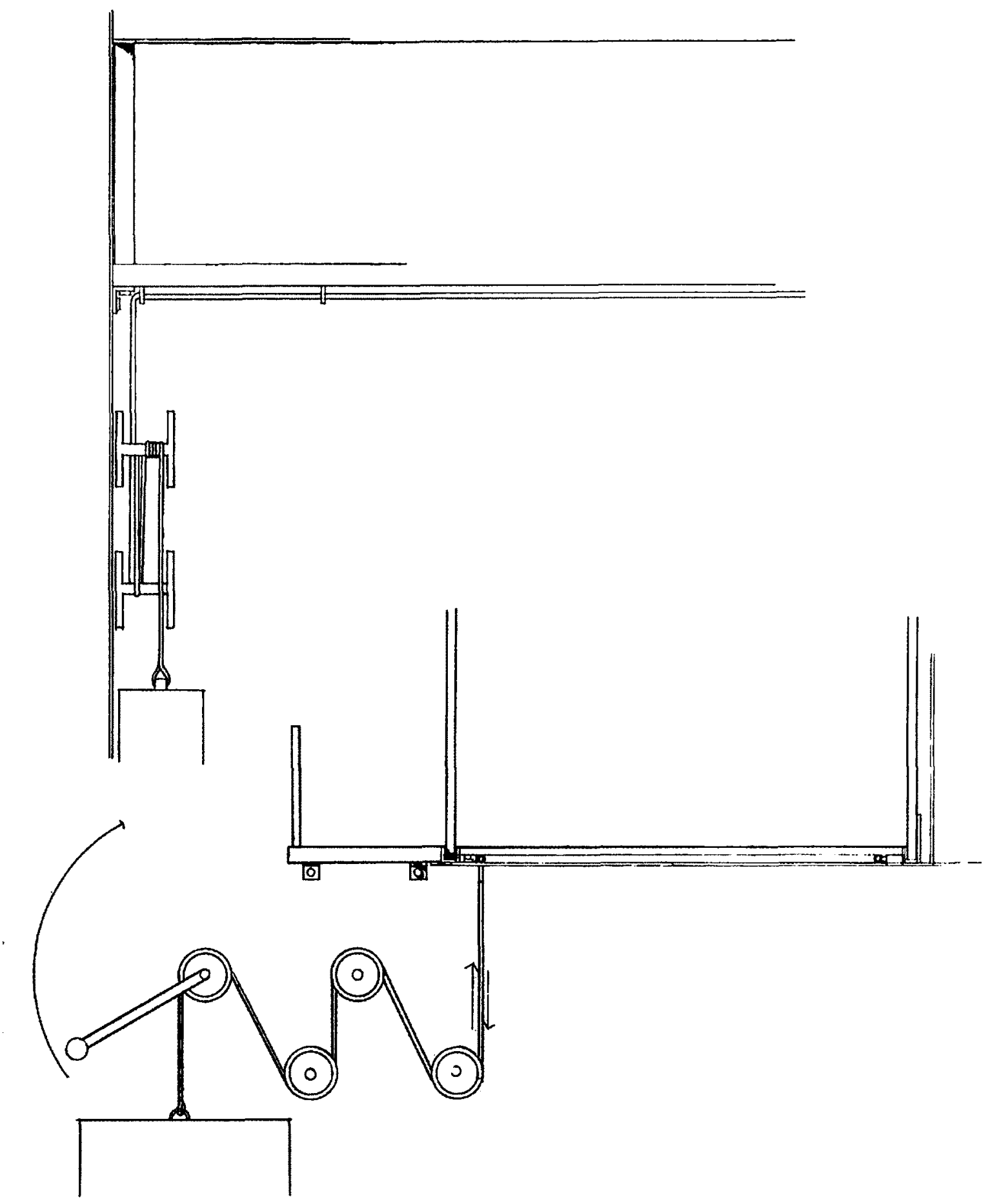

COUNTER-WEIGHTED PULLEY SYSTEM DETAIL 

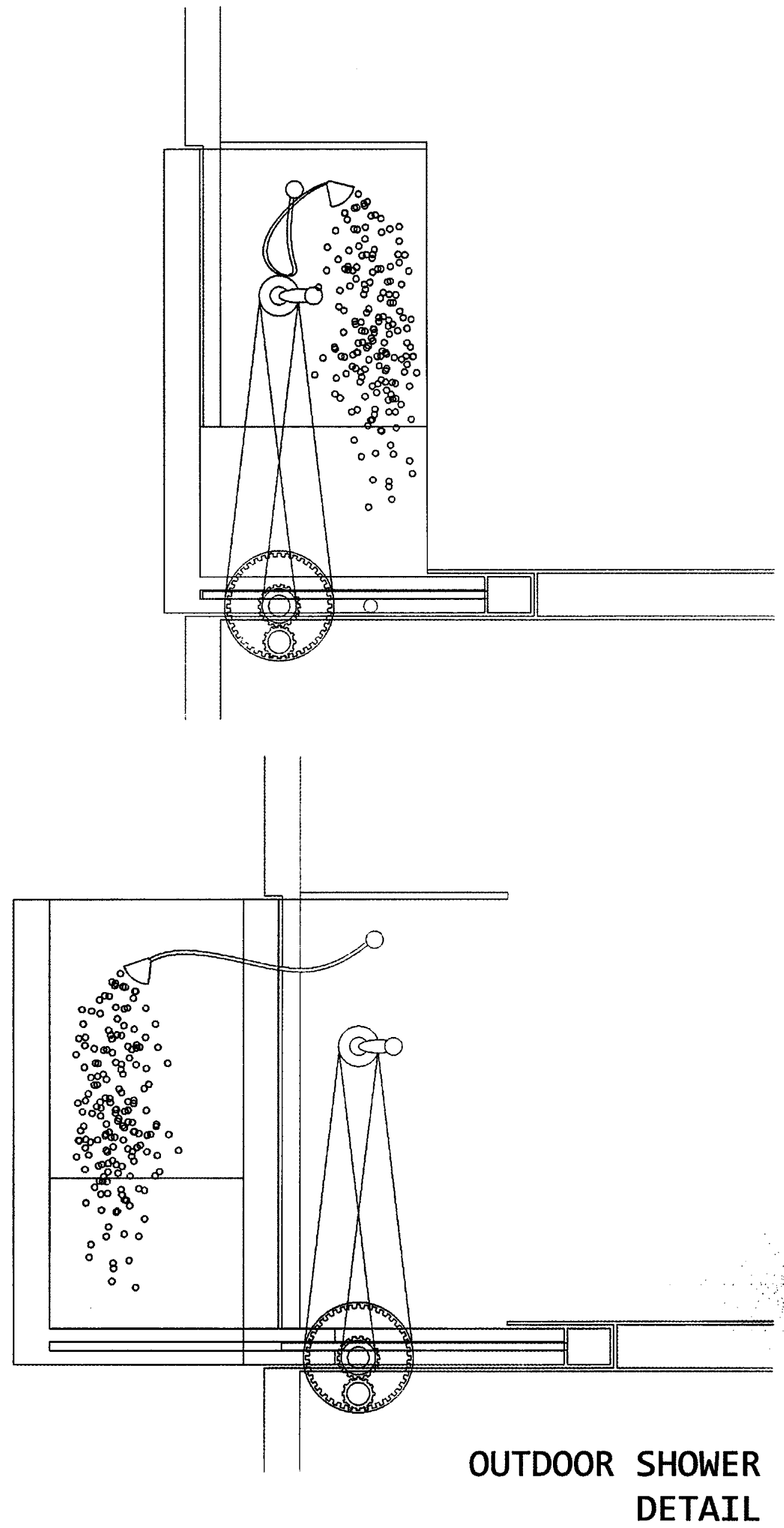


\section{conclusion}

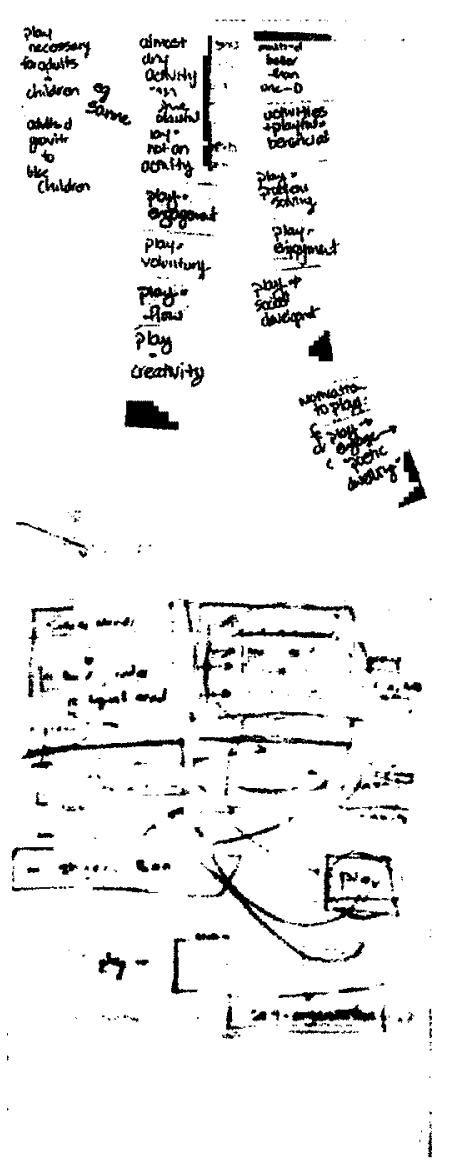

For the most part, the research, development and writing of this thesis has constituted a series of various types of play experiences. I've been absorbed in the task, at times forgetting to even break for a meal. It has been a thoroughly enjoyable process. It has been exciting to open my mind to fresh ideas. I've played with ideas, arranging various approaches to play and how it might be applied to architecture. I've played with materials and form. Throughout the process, I've occupied the space between what I know to be true about our built environment, and the imaginary potentialities that might exist architecturally when formal and material perceived constraints are challenged. My entire play experience was shaped and directed by my thesis advisor, Dr. Zhu. The framework that she provided allowed the fruits of play to take shape. My thought processes and understanding, through this play process, were greatly deepened and enhanced. Both my research and the process by which I engaged with it provide evidence for the benefits of play.

In the same way that reading and investigating new ideas in my research stimulated play for me, innovative formal frameworks can entice us to play. A house that provides both

unplanned potential] $\Gamma_{\text {yvonne kearns } 2012}$ 
the enticement and the opportunity for this type of play will cultivate new ideas about living. Architecture becomes the 'thesis advisor' for our daily research into ways of living. New meaning and ideas are read in the unique formal architectural framework, providing opportunity and direction for play.

Further play with the ideas put forward here might reveal how small changes to existing home environments might provide opportunities for play on a smaller scale. It is not feasible for the proposed house to be unilaterally available unilaterally. There is thus an opportunity for investigation into smaller and more transferable architectural frameworks for play, designs that can be inserted into the pre-existing domestic fabric.

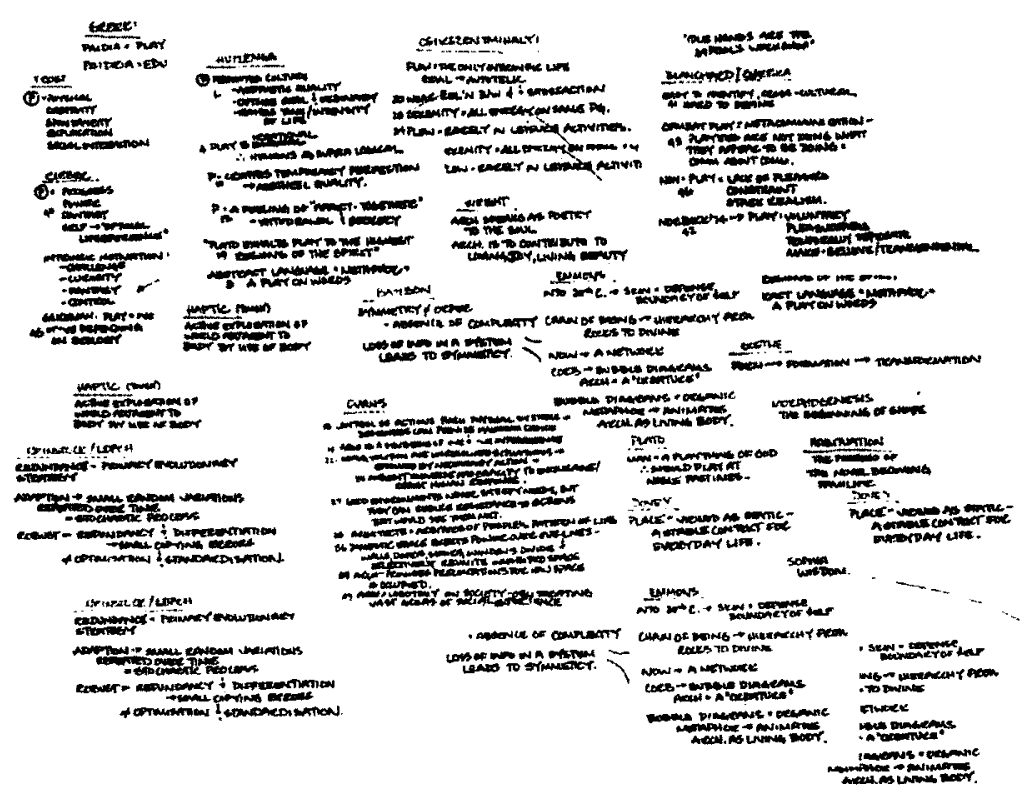

\footnotetext{
unplanned potential」 「yonne kearns 2012
} 


\section{${ }^{1}$ appendix: the site}

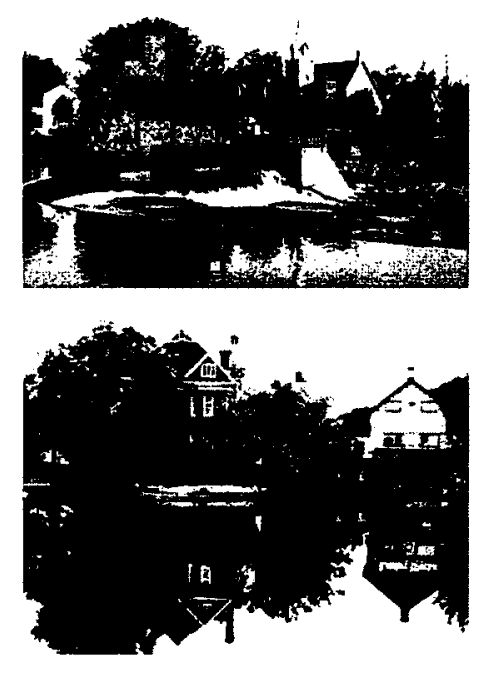

The site for this proposal is a lot in a development on the outskirts of the Town of Carleton Place, which is located approximately 40 kilometers west of ottawa on the TransCanada Highway. The town is attractive and rich in history, and is potentially a beautiful place to live. Carleton Place was first incorporated as a village in 1870 under the name of Morphy's Falls. The town is situated very close to Mississippi Lake. The Mississippi River, a tributary of the ottawa River, runs through the middle of the town.

The town was initially economically autonomous. Various businesses took advantage of the power available in the falls and built textile and lumber mills and a blacksmith foundry. Among the domestic architecture that remains from that time, there are two types of housing - that built for the mill owners and that built for the workers. High Street, which runs parallel to the river on the north side, is home to large brick dwellings set on expanses of green lawn. To the south of the river is a network of streets lined with small cottages.

Initially, modest homes were added to the town as the need arose, and blended into the existing fabric of the town.

unplanned potential」 $\Gamma_{\text {yvonne kearns } 2012}$ 
Later additions were on a larger scale and followed a prescribed monotonous pattern. The result is a fairly coherent core with individual distinct appendages stuck artlessly on to its edges. A visible barrier developed that marks the shift in strategy from growth that developed from within to growth imposed by exterior grand-scale developers.

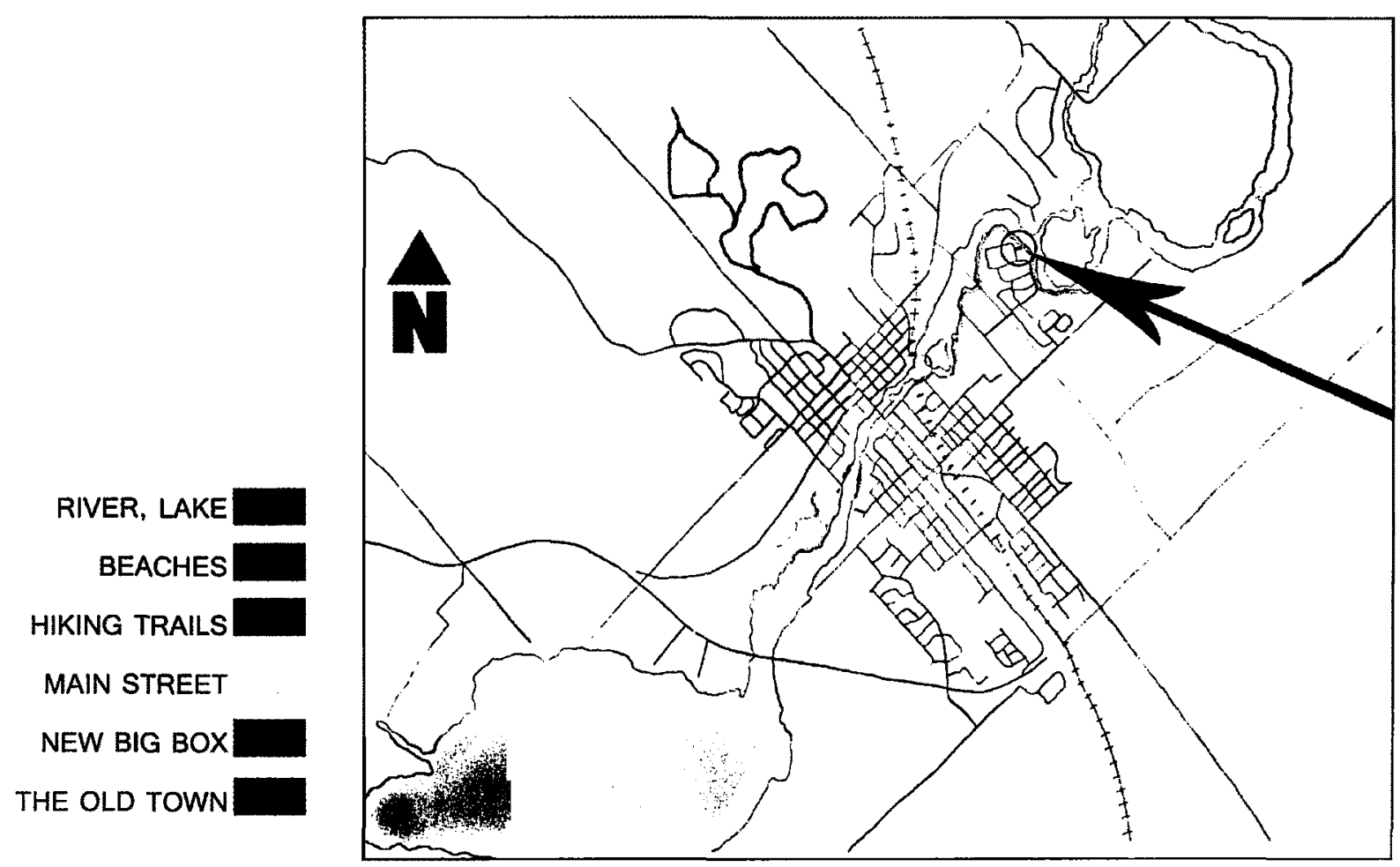

unplanned potential」 「Yvonne kearns 2012 

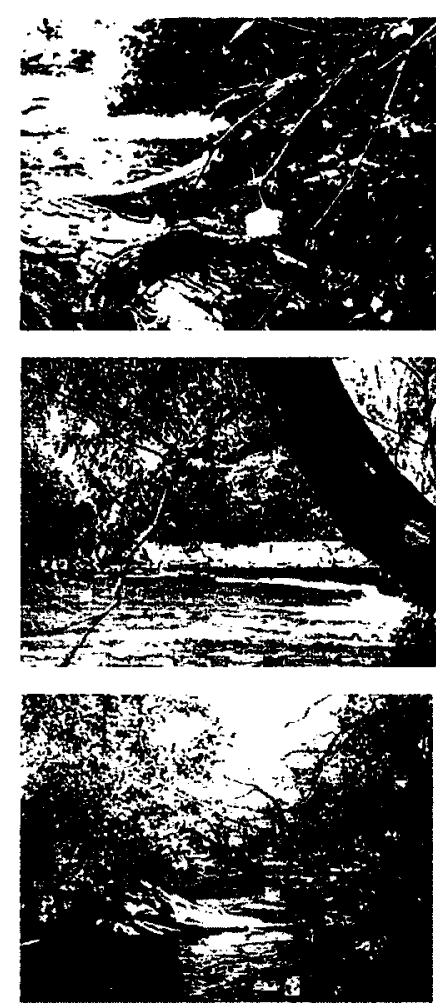

The mills and foundry eventually went out of business or moved to other locations. Lack of employment brought a certain amount of poverty to the town, which persists to this day. Currently, the town is home to the Canadian co-op wool Growers Limited, as well as a few technology companies. There has also been an explosion in the retail sector in recent years, partly due to the expansion of Highway 7, the major artery between Carleton Place and ottawa, from two lanes to four, which has transformed Carleton Place into a satellite commuter town. Recently, again as a result of the Highway 7 expansion, there has been a surge of residential development. Acres of farmland have been swallowed up by Home Depot, Walmart, Starbucks, Rona, Canadian Tire. Huge car dealerships have also been built.

The site for the playful house is in a new development that lies to the North-East of Carleton Place. It is situated between the old town and a bend in the Mississippi River that is home to some beautiful rapids and a view of the ruins of one of the old mills. The site is currently undeveloped, but is for sale by the developer. However, the proposed commercial home has completely discounted the beauty of the setting in its designs except by charging the potential home owner exorbitant fees for the lot's location, which backs onto the river.

The developer has largely predetermined the design of the house that will be constructed on the site, leaving very few choices to the purchaser. The potential for play that is presented by the river, the rapids, the hiking trails and the abundance of nature has not been tapped. The history and aesthetic of the old town is likewise ignored.
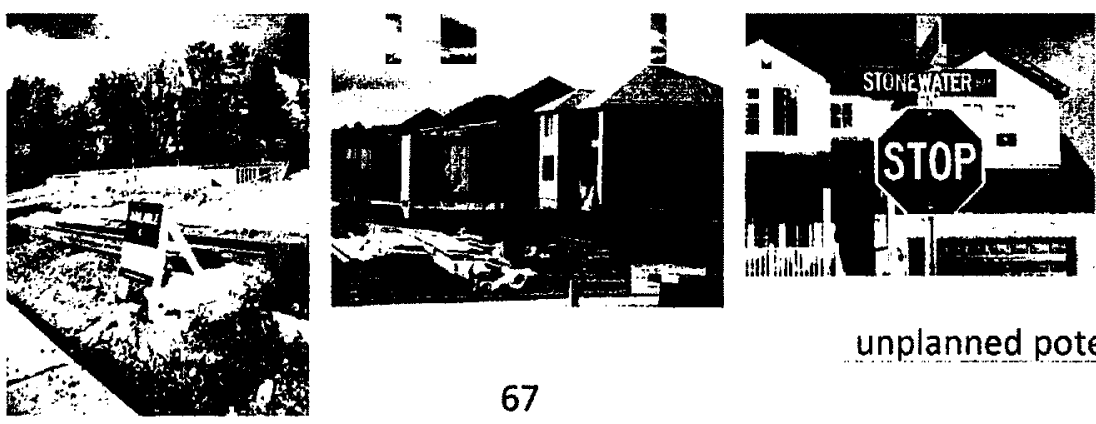

unplanned potential」 $\Gamma_{\text {yvonne kearns } 2012}$ 
1 Brown, Stuart L., and Christopher C. Vaughan, Play: How It Shapes the Brain, Opens the Imagination, and Invigorates the Soul ( New York: Avery, 2009), 18.

2 Tandy, C. A., "Children's Diminishing Play Space: a Study of Inter-generational Change in Children's Use of Their Neighbourhoods," Australian Geographical Studies 37, no. 2 (1999): $154-64$.

3 Brown, Play, 96.

4 Brown, Play, 97.

5 Bald, Sunil, and Yolande Daniels, "Fold, Crease, and Tear along Perforation: Domestic Protocols by Studio SUMO," The Journal of Architecture, (2004), 357.

Kent, Susan, ed., Domestic Architecture and the Use of Space: an Interdisciplinary Crosscultural Study (Cambridge England: Cambridge UP, 1990), 2.

6 Lerup, Lars, Planned Assaults (Cambridge, MA: MIT Press, 1987), 27.

7 Winnicott, D. W., Playing and Reality (New York: Basic, 1971), 71.

8 Winnicott, Playing, 53.

8 Winnicott, Playing, 71

10 Heidegger, Martin, Poetry, Language, Thought, (New York: Harper \& Row, 1971), 144.

"Heidegger, Poetry, 159.

12 Heidegger, Poetry 144.

13 Heidegger , Poetry, 145.

14 Blanchard, Kendall, Alyce Cheska, The Anthropology of Sport: an Introduction. S. Hadley, (MA: Bergin \& Garvey, 1985), 41.

15 Nachmanovitch, Stephen. "This Is Play," New Literary History 40 no, 1 (2009): 1-24.

16 Blanchard, Anthropology, 42.

17 Huizinga, Johan, Homo Ludens: a Study of the Play Element in Culture, (Boston: Beacon, 1970), 12.

${ }^{18}$ Huizinga, Homo, 8.

19 Winnicott, Playing, And Reality, (London, Routledge, 2009), 119.

20 Winnicott, Playing, (2005), 15.

21 Minnema, "Play and (Post)Modern Culture: An Essay on Changes in the Scientific Interest in the Phenomenon of Play," Cultural Dynamics 10.1 (1998), 21-47.

22 Kranjec, Alexander, Eileen R. Cardillo, Gwenda L. Schmidt, Matthew Lehet, and Anjan Chatterjee, "Deconstructing Events: The Neural Bases for Space, Time, and Causality," Journal of Cognitive Neuroscience , (2011), 1-16.

23 Brown, Play, 32.

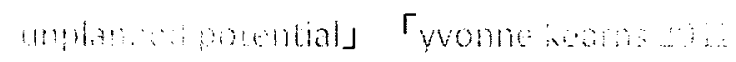


${ }^{24}$ Csikszentmihalyi, Mihaly, Finding Flow: the Psychology of Engagement with Everyday Life, (New York: Basic, 1997) ), 80.

25 Huizinga, Homo, 12.

${ }^{26}$ Frost, Joe, "Child's Play," Features. University of Texas, ( 2007) Web. 24 Oct. 2010.

27 Brown, Play, 38.

28 lbid., 34, 39.

${ }^{29}$ Kramer , Arthur F., Kirk I. Erickson, Stanley J. Colcombe, "Exercise, cognition, and the aging brain" Journal of applied psychology 101.4, (2006), $1237-1242$.

${ }^{30}$ Csikszentmihalyi, Finding, 66.

31 lbid., 46.

32 Brown, Play, 89.

33 lbid., 5, 173.

34 Mainemelis, C., and S. Ronson. "Ideas Are Born in Fields of Play: Towards a Theory of Play and Creativity in Organizational Settings." Research in Organizational Behavior 27 (2006), 81-131

35 Mainemelis et al, Jdeas, 81.

${ }^{36}$ Mainemelis et al, /deas, 82.

37 Mainemelis et al, /deas, 81 .

38 Wertheim, Margaret. "Margaret Wertheim on the Beautiful Math of Coral." Speech. Ted Talks. 2009. Ted Talks. Apr. 2009. Web. Oct. 2009.

39 Spariosu, Mihai, God of Many Names: Play, Poetry, and Power in Hellenic Thought from Homer to Aristotle, (Durham, NC: Duke UP, 1991), 53.

40 Brown, Play, 31.

41 Huizinga, Homo, 2.

42 Ibid., 10.

43 lbid., 15.

44 Ibid., 19.

${ }^{45}$ Sutton-Smith, Brian, and Anthony D. Pellegrini, The Future of Play Theory: a Multidisciplinary Inquiry into the Contributions of Brian Sutton-Smith, (Albany: State University of New York, 1995)

46 Huizinga, Homo, 9.

47 Rapoport, Amos, House Form and Culture, (Englewood Cliffs, NJ:Prentice-Hall, 1969), 12.

${ }^{48}$ Lang, Jon T, Creating Architectural Theory: the Role of the Behavioral Sciences in Environmental Design, (New York: Van Nostrand Reinhold, 1987), 81.

49 Lang, Creating 82.

50 Heidegger, Poetry, 159.

51 lbid., 162.

52 lbid., 161. 
53 Attfield, Judith, "Moving Home: Changing Attitudes to Residence and Identity," The Journal of Architecture 7 (2002),

${ }^{54}$ Friedman, Avi, The Adaptable House: Designing and Building for Change, (New York: McGraw-Hill, 2002), 24.

55 Friedman, Adaptable, 30.

56 Lerup, Planned, 16.

57 Lerup, Planned, 27.

58 Ingold, Tim. "The Textility of Making," Cambridge Joumal of Economics 34 (2010), 91 102.

${ }^{59}$ Schumacher, Michael, Oliver Schaeffer, and Michael-Marcus Vogt, Move: Dynamic Components and Elements in Architecture,( Basel: Birkhäuser, 2010), 8.

${ }^{60}$ Lerup, Lars, and Roger Montgomery, Building the Unfinished: Architecture and Human Action, (Beverly Hills, CA: Sage, 1977), 21.

61 Lozano-Hemmer, Rafael, "ALIEN RELATIONSHIPS FROM PUBLIC SPACE," Interview by Alex Adriaansens and Joke Brouwer, Transurbanism, 2002, Radio.

62 Attfield, Moving, 260.

63 Huizinga, Homo, 12.

64Wright, Frank Lloyd, An American Architecture, (New York: Horizon, 1955), 28.

${ }^{64}$ Friedman, Adaptable, ix

66 Allen et al, Place, 71.

${ }^{87}$ Rapoport, Amos, House, 9.

68 Allen et al, Place, 73.

${ }^{69}$ Cieraad, Irene, At Home: an Anthropology of Domestic Space, (Syracuse, NY: Syracuse UP, 2006), 73.

70 Allen et al, Place, 79.

71 Allen et al, Place, 79.

12 Allen et al, Place, 79.

73 Attfield, Moving, 259.

${ }^{74}$ Hektner, Joel M., Jennifer A. Schmidt, and Mihaly Csikszentmihalyi, Experience Sampling Method: Measuring the Quality of Everyday Life, (Thousand Oaks, CA: Sage Publications, 2007), 133.

75 Kent, Domestic, 2.

76 Heidegger, Poetry, 159.

7 Ingold, Tim, "Materials against Materiality," Archaeological Dialogues, (Cambridge University Press 14, 2007), 1-16.

78 Ingold, Materials, 3.

79 Kronenburg, R., Joseph Lim, and Wong Yunn. Chii, Transportable Environments 2, (London: Spon, 2003), 149.

80 Kronenburg , Transportable, 149. 


\title{
list of figures and quotes
}

\author{
6 poetry of engagement \\ acrylic on canvas \\ Yvonne Kearns \\ $7 \quad$ Plastic Play House \\ alibaba.com \\ 8 Cardboard Box \\ thedailygreen.com \\ 11 definition \\ all definitions, unless otherwise \\ stated, are from the Merriam-Webster dictionary \\ www.merriam-webster.com/dictionary \\ 12 William Shakespeare \\ As You Like It \\ Act II Scene viii \\ $14 \quad 3^{\text {rd }}$ Place \\ 2007 World Rodeo Championships \\ Ottawa, Ontario \\ Richard Matthews \\ Used with Permission \\ 19 Crochet story \\ Margaret Wertheim \\ Ted Talks \\ Www.tedtalks.com \\ Crochet photo \\ needlework and photo \\ Yvonne Kearns \\ Hyperbolic space model \\ page.mi. fu-berlin.de/ \\ 20 all photos \\ Yvonne Kearns
}

71

unplanned potential」 「yvonne kearns 2012 


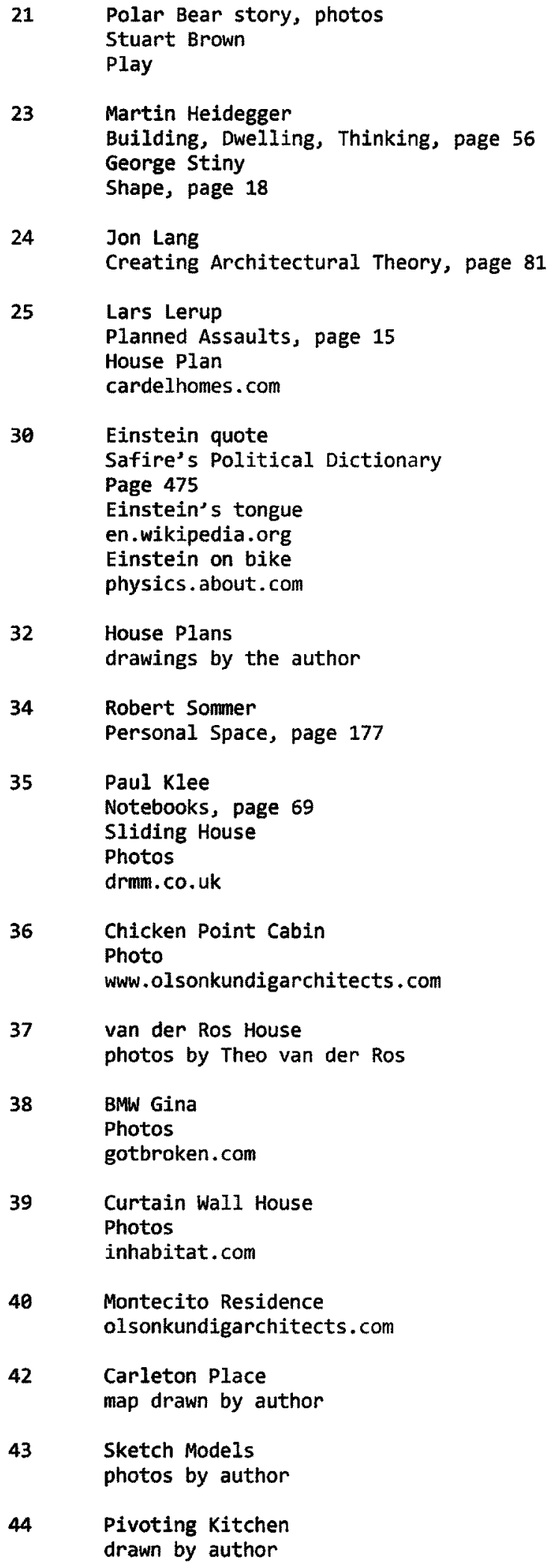


46

Sketch Model

photos by author

47 Sketch Models

photos by author

$48 \quad$ Folded Paper

drawing and photos by author

5065 Proposed House

drawings by author

66 Carleton Place Photos author

67 Map of Carleton Place

drawn by author

68

Site Photos

by author 


\section{bibliography}

Allen, Gerald, Donlyn Lyndon, Charles Willard Moore, Charles Willard Moore, and Charles Willard Moore. The Place of Houses. New York A.0: Holt, Rinehart \& Winston, 1974. Print.

Arendt, Hannah. The Human Condition. Chicago: University of Chicago, 1998. Print.

Attfield, Judith. "Moving Home: Changing Attitudes to Residence and Identity." The Journal of Architecture 7 (2002). Print.

Bald, Sunil, and Yolande Daniels. "Fold, Crease, and Tear along Perforation: Domestic Protocols by Studio SUMO." The Journal of Architecture 9 (2004). Print.

Barrios, José Luis,, and Rafael Lozano-Hemmer. Rafael Lozano-Hemmer: ALgunas Cosas Pasan Más Veces Que Todo EL Tiempo = Rafael LozanoHemmer: Some Things Happen More Often than ALL of the Time : La Biennale Di Venezia: 52. Esposizione Internazionale D'Arte [México]. Madrid: Turner, 2007. Print.

Blanchard, Kendall, and Alyce Taylor. Cheska. The Anthropology of Sport: an Introduction. S. Hadley, MA: Bergin \& Garvey, 1985. Print.

\section{4}


Brown, Stuart L., and Christopher C. Vaughan. PLay: How It Shapes the Brain, Opens the Imagination, and Invigorates the Soul. New York: Avery, 2009. Print.

Brown, Stuart. "Why Didn't the Wild Polar Bear Eat the Husky?" National Institute For Play. Web. 17 Sept, 2010. <http://Www.nifplay.org/>.

Chatfield, Tom. " 7 Ways Games Reward the Brain." Speech. Ted Talks. 13 Nov. 2010. Ted Talks. Nov. 2010. Web. 〈http://Www.ted.com/talks〉.

Cherfas, Jeremy, and Roger Lewin. Not Work Alone: a Cross-cultural View of Activities Superfluous to Survival. Beverly Hills, CA: Sage Publications, 1980. Print.

Cieraad, Irene. At Home: an Anthropology of Domestic Space. Syracuse, NY: Syracuse UP, 2006. Print.

Csikszentmihalyi, Mihaly. Finding Flow: the Psychology of Engagement with Everyday Life. New York: Basic, 1997. Print.

Csikszentmihalyi, Mihaly. "If We Are so Rich, Why Aren't We Happy?" American Psychologist 54.10 (1999): 821-27. Print.

Dovey, Kim. Becoming PLaces: Urbanism/architecture/identity/power. London: Routledge, 2010. Print.

Emmons, Paul. "Embodying Networks: Bubble Diagrams and the Image of Modern Organicism." The Journal of Architecture 11.4 (2006): 44161. Print.

Erikson, Erik H. Toys and Reasons: Stages in the Ritualization of Experience. New York: Norton, 1977. Print.

Evans, Robin. Translation from Drawing to Building and Other Essays. London: Architectural Association, 1997. Print. 
Forencich, Frank. Play as If Your Life Depends on It: Functional Exercise and Living for Homo Sapiens. Seattle, WA: GoAnimal, 2003. Print.

Friedman, Avi. The Adaptable House: Designing and Building for Change. New York: McGraw-Hil1, 2002. Print.

Heidegger, Martin. Poetry, Language, Thought. New York: Harper \& Row, 1971. Print.

Hektner, Joel M., Jennifer A. Schmidt, and Mihaly Csikszentmihalyi. Experience Sampling Method: Measuring the Quality of Everyday Life. Thousand Oaks, CA: Sage Publications, 2007. Print.

Hildebrand, Grant. Origins of Architectural PLeasure. Berkeley: University of California, 1999. Print.

Huizinga, Johan. Homo Ludens: a Study of the Play Element in Culture. Boston: Beacon, 1970. Print.

Ingold, Tim. "Materials against Materiality." Archaeological Dialogues Cambridge University Press 14 (2007): 1-16. Print.

Ingold, Tim. "The Textility of Making." Cambridge Journal of Economics 34 (2010): 91-102. Print.

Kent, Susan, ed. Domestic Architecture and the Use of Space: an Interdisciplinary Cross-cultural Study. Cambridge [England: Cambridge UP, 1990. Print.

Kranjec, Alexander, Eileen R. Cardillo, Gwenda L. Schmidt, Matthew Lehet, and Anjan Chatterjee. "Deconstructing Events: The Neural Bases for Space, Time, and Causality." Journal of Cognitive Neuroscience (2011): 1-16. Print.

Kronenburg, R., Joseph Lim, and Wong Yunn. Chii. Transportable Environments 2. London: Spon, 2003. Print. 
Kundig, Tom, and Dung Ngo. Tom Kundig: Houses. New York: Princeton Architectural, 2006. Print.

Lang, Jon. Designing for Human Behavior: Architecture and the Behavioral Sciences. Stroudsburg, PA: Dowden, Hutchinson and Ross, 1974. Print.

Lang, Jon T. Creating Architectural Theory: the Role of the Behavioral Sciences in Environmental Design. New York: Van Nostrand Reinhold, 1987. Print.

Lerup, Lars, and Roger Montgomery. Building the Unfinished: Architecture and Human Action. Beverly Hills, CA: Sage, 1977. Print.

Lerup, Lars. PLanned Assault. Cambridge: MIT, 1987. Print.

Lozano-Hemmer, Rafael. "A Conversation between José Luis Barrios and Rafael Lozano-Hemmer." Interview by José Barrios. Sala De Arte Público Siquieros (SAPS). Mexico City, 20 Apr. 2005. Radio. Transcript.

Lozano-Hemmer, Rafael. "ALIEN RELATIONSHIPS FROM PUBLIC SPACE." Interview by Alex Adriaansens and Joke Brouwer. Transurbanism. 2002. Radio. Lynn, Greg, ed. Folding in Architecture. Chichester, west Sussex: WileyAcademy, 2004. Print.

Mainemelis, C., and S. Ronson. "Ideas Are Born in Fields of Play: Towards a Theory of Play and Creativity in Organizational Settings." Research in Organizational Behavior 27 (2006): 81-131. Print.

Nachmanovitch, Stephen. "This Is Play." New Literary History 40.1 (2009): 1-24. Print.

Norberg-Schulz, Christian. Genius Loci: towards a Phenomenology of Architecture. New York: Rizzoli, 1980. Print. 
Rapoport, Amos. House Form and Culture. Englewood Cliffs, NJ: PrenticeHall, 1969. Print.

Schönauer, Norbert. 6000 Years of Housing. New York [u.a.: Norton, 2000. Print.

Sewell, John. Houses and Homes: Housing for Canadians. Toronto: James Lorimer \&, 1994. Print.

Sommer, Robert. Personal Space; the Behavioral Basis of Design. Englewood Cliffs, NJ: Prentice-Hall, 1969. Print.

Spariosu, Mihai. God of Many Names: Play, Poetry, and Power in Hellenic Thought from Homer to Aristotle. Durham, NC: Duke UP, 1991. Print.

Squatriglia, Chuck. "BMW Builds a Shape-shifting Car out of Cloth." Wired. 10 June 2008. Web. 03 May 2011. 〈http://wired.com〉.

Stiny, George, and James Gips. "Shape Grammars and the Generative Specification of Painting and Sculpture." Print. Rpt. in The Best Computer Papers of 1971. Philadelphia: O R Petrocelli, 1972. 12535. Print.

Stiny, George. Shape: Talking about Seeing and Doing. Cambridge, MA: MIT, 2006. Print.

Sutton-Smith, Brian, and Anthony D. Pellegrini. The Future of Play Theory: a Multidisciplinary Inquiry into the Contributions of Brian Sutton-Smith. Albany: State University of New York, 1995. Print.

Sutton-Smith, Brian. The Ambiguity of Play. Cambridge, MA: Harvard UP, 1997. Print. 
Tandy, C. A. "Children's Diminishing Play Space: a Study of Intergenerational Change in Children's Use of Their Neighbourhoods." Australian Geographical Studies 37.2 (1999): 154-64. Print.

Wertheim, Margaret. "Margaret Wertheim on the Beautiful Math of Coral." Speech. Ted Talks. 2009. Ted Talks. Apr. 2009. Web. Oct. 2009.

Winnicott, D. W. Playing and Reality. New York: Basic, 1971. Print.

Wright, Frank Lloyd. An American Architecture. New York: Horizon, 1955. Print.

Wright, Iovanna Lloyd. Architecture Man in Possession of His Earth. London: MacDonald, 1962. Print. 